\title{
The Importance of Tropical Sea Surface Temperature Patterns in Simulations of Last Glacial Maximum Climate*
}

\author{
JeFFREY H. Yin AND DAVID S. BATTISTI \\ Department of Atmospheric Sciences, University of Washington, Seattle, Washington
}

(Manuscript received 18 June 1999, in final form 29 February 2000)

\begin{abstract}
Prescribed SST experiments are performed using the National Center for Atmospheric Research's Community Climate Model version 3 general circulation model to isolate the contribution of the tropical SSTs reconstructed by the Climate, Long-range Investigation, Mapping and Prediction study (CLIMAP) to the modeled global atmospheric circulation anomalies at the Last Glacial Maximum (LGM). The changes in tropical SST patterns cause changes in tropical convection that force large ( $>300 \mathrm{~m}$ in $500-\mathrm{mb}$ geopotential height) changes in Northern Hemisphere wintertime circulation. These midlatitude circulation changes occur despite the small $\left(1^{\circ} \mathrm{C}\right)$ change in the mean tropical SST between the present and the CLIMAP reconstruction. In fact, the midlatitude circulation changes due to the difference in the tropical SST pattern between the present and the CLIMAP reconstruction are greater than the circulation changes due to a uniform tropical SST cooling of $3^{\circ} \mathrm{C}$ or those due to the presence of the LGM ice sheets. The circulation anomalies due to the change in tropical SST patterns result in a wintertime warming (cooling) of $8^{\circ} \mathrm{C}\left(8^{\circ} \mathrm{C}\right)$ over the Laurentide (Fennoscandian) ice sheet and a decrease (increase) in annual mass balance of over $1000 \mathrm{~mm} \mathrm{yr}^{-1}\left(800 \mathrm{~mm} \mathrm{yr}^{-1}\right)$ along the southern margin of the ice sheet. These results demonstrate that detailed knowledge of tropical SST patterns is needed in order to produce reliable simulations of LGM climate. In the appendix, it is shown that the lion's share of the midlatitude circulation changes are due to SST gradients in the northern Tropics, and that the physics involved in the teleconnection between tropical SST forcing and midlatitude circulation changes is rich and highly nonlinear.
\end{abstract}

\section{Introduction}

In today's climate, some of the largest reorganizations of atmospheric circulation occur as a result of the changes in tropical sea surface temperature (SST) patterns associated with El Niño-Southern Oscillation (ENSO). The typical atmospheric response to the warm SST anomaly in the eastern equatorial Pacific, which constitutes the warm phase of ENSO, includes an anomalously deep trough over the North Pacific and an anomalously high ridge over western Canada, with associated temperature and precipitation patterns observed around the globe (Ropelewski and Halpert 1996; Zhang et al. 1997). These changes in atmospheric circulation result from the propagation of planetary-scale waves from regions of anomalous upper-level divergence associated with the changes in tropical convection forced by ENSO SST anomalies.

\footnotetext{
* Joint Institute for the Study of the Atmosphere and Ocean Contribution Number 699.

Corresponding author address: Jeffrey Yin, JISAO, University of Washington, Box 354235, Seattle, WA 98195-4235.

E-mail: jyin@atmos.washington.edu
}

Given the importance of tropical SST patterns in determining present-day atmospheric circulation, one might expect that tropical SSTs could play an important role in determining the circulation in past climates, such as the Last Glacial Maximum (LGM), as well. Currently, the only global SST reconstruction for the LGM is that of the Climate, Long-range Investigation, Mapping and Prediction (CLIMAP) Project Members (1981, hereafter CLIMAP 1981), which was constructed by using the distribution of foraminifera species at the LGM to infer SSTs. The tropical SSTs of the CLIMAP reconstruction, which are approximately $1^{\circ} \mathrm{C}$ cooler in the mean than present-day tropical SSTs, have been called into question based on atmospheric general circulation model (GCM) results indicating that they are not consistent with lowered tropical snow lines (Rind and Peteet 1985) as well as evidence from foraminiferal $\delta^{18} \mathrm{O}$ (Curry and Oppo 1997), $\delta^{18} \mathrm{O}$ and $\mathrm{Sr} / \mathrm{Ca}$ ratios from Barbados corals (Guilderson et al. 1994), $\delta^{18} \mathrm{O}$ from tropical ice cores (Thompson et al. 1995), and noble gases in a Brazil aquifer (Stute et al. 1995) that the Tropics were $4^{\circ}-6^{\circ} \mathrm{C}$ cooler at the LGM than at present. Mix et al. (1999) have used a revised transfer function method involving foraminiferal assemblages to produce a new LGM SST reconstruction for the tropical Atlantic and eastern equatorial Pacific with temperatures over $5^{\circ} \mathrm{C}$ cooler than at 
present along the equator in the eastern Atlantic and Pacific. Hostetler and Mix (1999) have used this new SST reconstruction as a boundary condition for an atmospheric GCM simulation of LGM climate, which shows that the new reconstruction resolves some, but not all, of the conflicts with terrestrial paleodata associated with the CLIMAP SSTs.

The CLIMAP tropical SSTs are also inconsistent with the SSTs predicted by mixed layer ocean models with present-day ocean heat transport coupled to atmospheric GCMs run with LGM boundary conditions for land ice, greenhouse gases, and orbital parameters. While the CLIMAP reconstruction has little change in mean tropical SST, mixed layer ocean models coupled to atmospheric GCMs typically predict a mean cooling of tropical SSTs of approximately $2^{\circ} \mathrm{C}$ (Broccoli and Manabe 1987; Dong and Valdes 1998; Broccoli 2000; this work), and up to $5.5^{\circ} \mathrm{C}$ in one study (Webb et al. 1997). The CLIMAP reconstruction also has warmer SSTs than at present in the subtropical gyres of the Pacific, which are not found in any of the mixed layer ocean simulations mentioned above. While a mixed layer ocean model cannot capture the effects of changes in ocean circulation, a recent experiment with a coupled atmosphere-ocean model with LGM boundary conditions found a tropical cooling of $4^{\circ}-6^{\circ} \mathrm{C}$ relative to the present (Bush and Philander 1998).

Although the simulation of changes in tropical SSTs by mixed layer ocean models cannot be considered accurate, important differences between the LGM atmospheric circulations simulated by GCMs with prescribed CLIMAP SSTs and by GCMs with a mixed layer ocean model can be noted. The prescribed CLIMAP SST experiments of Rind (1987), Joussaume (1993), Hall et al. (1996), and this study all exhibit anomalous lows (relative to present-day control experiments) in Northern Hemisphere $(\mathrm{NH})$ winter 500-mb geopotential height centered over both the North Pacific and the North Atlantic, with an anomalous high over North America; this pattern is shifted somewhat to the west in the Rind (1987) simulation, and somewhat to the east in the Joussaume (1993) simulation. In contrast, LGM simulations performed with GCMs coupled to mixed layer ocean models (Broccoli and Manabe 1987; Dong and Valdes 1998; this work) do not exibit this pattern; instead, the dominant pattern in 500-mb geopotential height in this region is a high anomaly upstream of the Laurentide ice sheet and a low anomaly downstream of the ice sheet. This suggests that the difference between prescribed and calculated SSTs in these LGM experiments could be responsible for large changes in the simulated atmospheric circulation.

The prescribed SST experiments of this study that aim to isolate the effects of tropical SST and ice sheet elevation on LGM climate owe their inspiration to the studies of Rind (1987) and Broccoli and Manabe (1987) on the influence of different boundary conditions on the atmospheric circulation of the LGM. Rind (1987) begins with a control simulation of the current climate with prescribed SSTs and, in successive experiments, adds 1) the LGM SSTs of CLIMAP (1981), 2) $10 \mathrm{~m}$ of land ice in regions covered by ice at the LGM according to CLIMAP (1981), and 3) ice sheets of their full LGM thickness according to CLIMAP (1981). While Rind (1987) does examine the effects of changing global SSTs from present day to CLIMAP (1981) LGM values, the most important new contribution of the present study is the isolation of the effect of the tropical SSTs of CLIMAP (1981) on the LGM atmospheric circulation. The model experiments, their results, and implications are described in the following sections.

\section{Model experiments}

The atmospheric GCM used in the model experiments described in this paper is the National Center for Atmospheric Research's (NCAR's) Community Climate Model version 3.6 (CCM3), which is described in detail in Kiehl et al. (1996). It is a spectral model with a triangular truncation in the horizontal and a hybrid sigma-pressure coordinate in the vertical. The resolution we employed truncates the solution at total wavenumber 31 and zonal wavenumber 15 (approximately a $3.75^{\circ}$ by $7.5^{\circ}$ transform grid), with 18 vertical levels. The model includes a diurnal cycle of radiation and a treatment of land surface processes, and produces a credible simulation of today's tropospheric circulation (Hurrell et al. 1998).

All of the LGM model experiments (LGM CLIMAPSST, LGM Y2KSST, LGM CLIMAPSST COOL, LGM Y2KSST COOL, LGM Y2KSST FLAT, LGM SLAB) except for one were performed using appropriate LGM boundary conditions for ice sheet elevation and extent (from the Peltier 1994 reconstruction), the seasonally varying insolation (calculated for $21 \mathrm{ka} \mathrm{BP}$ ), and concentrations of greenhouse gases (including a $\mathrm{CO}_{2}$ concentration of $200 \mathrm{ppm}$ ). The exception is LGM Y2KSST FLAT that was performed with the same LGM boundary conditions except that the LGM ice sheets were reduced to the elevation of present-day topography while retaining the LGM ice extent (i.e., a zero thickness ice sheet). The present-day model experiments (CONTROL, CONTROL SLAB) used present-day topography and insolation and a $\mathrm{CO}_{2}$ concentration of $355 \mathrm{ppm}$.

The prescribed SST distributions used were either the present-day SST climatology, the CLIMAP (1981) reconstruction of SST at the LGM, or a hybrid of the two. The difference between the CLIMAP reconstruction and the present-day climatology is shown in Fig. 1. Note the warm anomalies in the subtropical Pacific and the large increases in sea ice extent in high latitudes indicated by the negative anomalies there.

Model experiment CONTROL uses the present-day SST climatology, while LGM CLIMAPSST uses the CLIMAP SST reconstruction. The SST prescribed in experiment LGM Y2KSST consists of the CLIMAP re- 

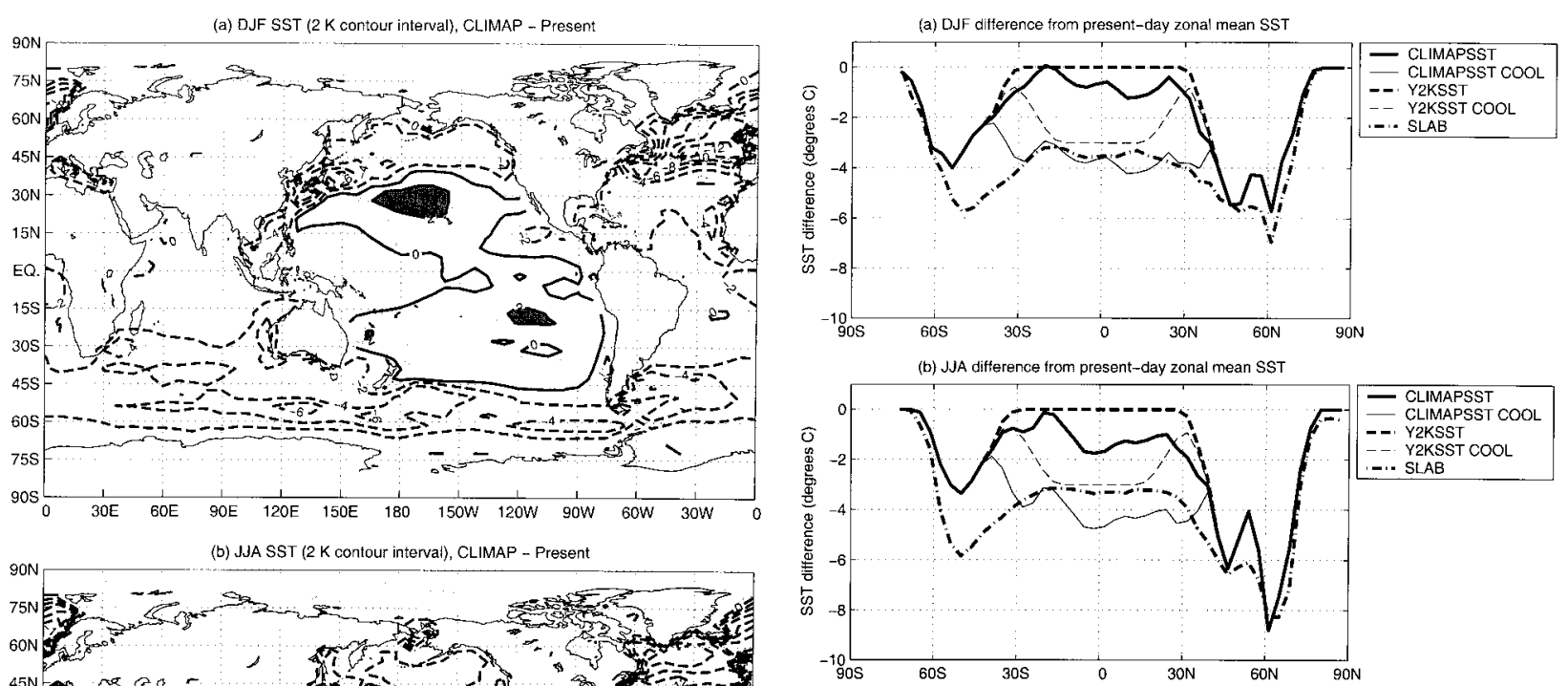

FIG. 2. The zonally averaged difference between present-day SST and the prescribed SST in experiments LGM CLIMAPSST (thick solid line), LGM CLIMAPSST COOL (thin solid line), LGM Y2KSST (thick dashed line), and LGM Y2KSST COOL (thin dashed line) in two seasons: (a) DJF and (b) JJA. The thick dashed-dotted line shows the zonally averaged difference in calculated SST between experiments LGM SLAB and CONTROL SLAB.

sea ice distribution is not affected. Figure 2 shows the zonally averaged differences between the SSTs used for the four LGM experiments described above and the present-day SSTs used in the CONTROL run. For reference, the zonally averaged difference in computed SSTs between the LGM SLAB and CONTROL SLAB runs (described below) is also shown.

A mixed layer ocean model is used to calculate SSTs construction poleward of $40^{\circ} \mathrm{S}$ and $40^{\circ} \mathrm{N}$, with present SSTs between $30^{\circ} \mathrm{S}$ and $30^{\circ} \mathrm{N}$ and a linear blend of the two between $30^{\circ}$ and $40^{\circ}$ latitude. This captures all of the sea ice extent of the CLIMAP reconstruction, while keeping present-day SSTs in the Tropics. Experiments LGM CLIMAPSST COOL and LGM Y2KSST COOL use the same prescribed SSTs as LGM CLIMAPSST and LGM Y2KSST, respectively, with a cooling added in the deep Tropics: the cooling is prescribed to be $3^{\circ} \mathrm{C}$ from $14^{\circ} \mathrm{S}$ to $14^{\circ} \mathrm{N}$, with a reduction in magnitude poleward of these latitudes of Gaussian form with a characteristic length scale of $10^{\circ}$ latitude. The prescribed cooling is set to zero poleward of $40^{\circ} \mathrm{S}-40^{\circ} \mathrm{N}$, so the in model experiments CONTROL SLAB and LGM SLAB. This is a simple thermodynamic mixed layer ocean with a prescribed seasonal variation of the mixed layer depth that is derived from today's climatology from Levitus (1982) and a prescribed ocean heat flux convergence implied by the surface heat fluxes from our CONTROL prescribed SST experiment.

A summary of the boundary conditions used in the experiments described above is found in Table 1. Prescribed SST experiments were run for $20 \mathrm{yr}$, and computed SST experiments for $30 \mathrm{yr}$, with output averaged over the last $17 \mathrm{yr}$ of each run. In both computed SST

TABLE 1. Summary of boundary conditions used in the GCM experiments.

\begin{tabular}{|c|c|c|c|c|c|}
\hline Experiment & Topography & Insolation & $\mathrm{CO}_{2}(\mathrm{ppm})$ & Extratropical SST & Tropical SST \\
\hline CONTROL & Present & Present & 355 & Present & Present \\
\hline LGM CLIMAPSST & Peltier (1994) & $21 \mathrm{ka} \mathrm{BP}$ & 200 & CLIMAP & CLIMAP \\
\hline LGM CLIMAPSST COOL & Peltier (1994) & $21 \mathrm{ka} \mathrm{BP}$ & 200 & CLIMAP & CLIMAP $-3^{\circ} \mathrm{C}$ \\
\hline LGM Y2KSST & Peltier (1994) & $21 \mathrm{ka} \mathrm{BP}$ & 200 & CLIMAP & Present \\
\hline LGM Y2KSST COOL & Peltier (1994) & $21 \mathrm{ka} \mathrm{BP}$ & 200 & CLIMAP & Present $-3^{\circ} \mathrm{C}$ \\
\hline LGM Y2KSST FLAT & Present & $21 \mathrm{ka} \mathrm{BP}$ & 200 & CLIMAP & Present \\
\hline CONTROL SLAB & Present & Present & 355 & Slab ocean & Slab ocean \\
\hline LGM SLAB & Peltier (1994) & $21 \mathrm{ka} \mathrm{BP}$ & 200 & Slab ocean & Slab ocean \\
\hline
\end{tabular}




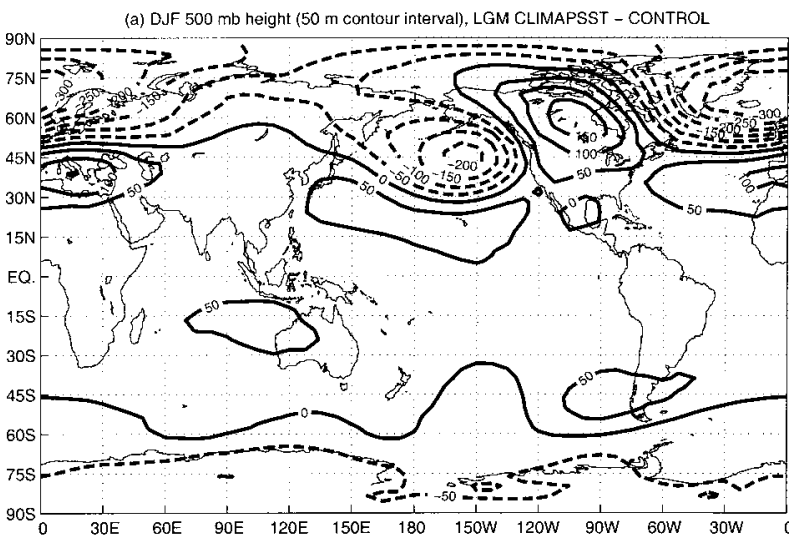

(b) JJA $500 \mathrm{mb}$ height (50 $\mathrm{m}$ contour inteval), LGM CLIMAPSST - CONTROL

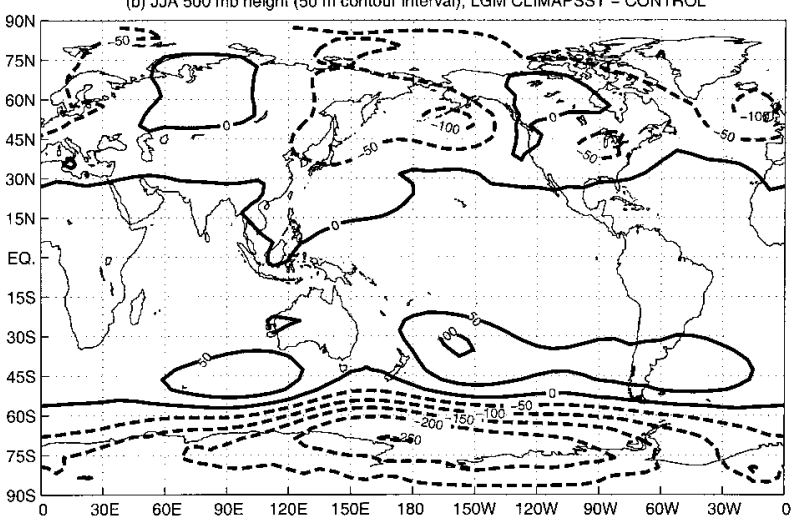

FIG. 3. Difference in 500-mb geopotential height between CCM3 experiments LGM CLIMAPSST and CONTROL in two seasons: (a) DJF and (b) JJA. The contour interval is $50 \mathrm{~m}$ with dashed lines indicating negative contours.

experiments, the globally averaged surface temperature reached an equilibrium annual cycle within $13 \mathrm{yr}$. The $17-y r$ averaging period provides a high level of statistical significance in our results. For example, a $t$ test on the difference between sample means for experiments LGM CLIMAPSST and LGM Y2KSST shows that differences in December-January-February (DJF) 500-mb height larger than $50 \mathrm{~m}$ are significant at the $95 \%$ level except in a few small regions north of $45^{\circ} \mathrm{N}$; the threshold for significance is typically between 20 and $40 \mathrm{~m}$ in the NH midlatitudes (and never exceeds $65 \mathrm{~m}$ ) and is less than $10 \mathrm{~m}$ throughout the Tropics. The results of all experiments are described in the following section.

\section{Model results and analysis}

The difference between experiments LGM CLIMAPSST and CONTROL is due to the combination of changes in SST, ice sheet extent and height, greenhouse gases, and insolation between the LGM and present, according to the reconstructions of LGM boundary conditions described above. The change in DJF 500-mb height shown in Fig. 3 shows a deep low anomaly over the North Pacific, a high anomaly over North America,

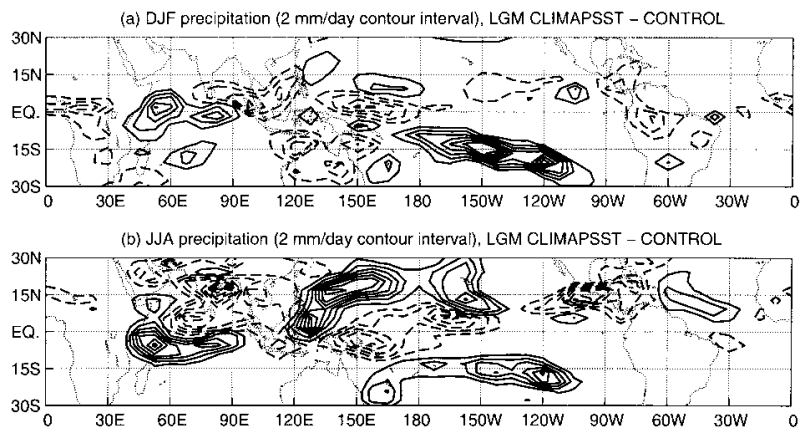

FIG. 4. Difference in precipitation between CCM3 experiments LGM CLIMAPSST and CONTROL in two seasons: (a) DJF and (b) JJA. The contour interval is $2 \mathrm{~mm}^{\text {day }}{ }^{-1}$ with dashed lines indicating negative contours and the zero contour omitted.

and a low anomaly over the North Atlantic, similar to what was found by Rind (1987), Joussaume (1993), and Hall et al. (1996). The change in DJF precipitation shown in Fig. 4 exhibits five features in precipitation that can be directly linked to changes in tropical SST gradients shown in Fig. 1: 1) a large increase in precipitation in the South Pacific convergence zone (SPCZ) near $15^{\circ} \mathrm{S}$ in the central Pacific accompanied by a decrease over northern Australia, associated with the change in the longitudinal SST gradient near $15^{\circ} \mathrm{S}$ (with cold anomalies near Australia and warm anomalies in the eastern Pacific; 2) a decrease in precipitation from India to the Philippines accompanied by an increase across the equatorial Indian Ocean, associated with the change in the latitudinal and longitudinal SST gradients in the northern Indian Ocean (with cold anomalies over $4^{\circ} \mathrm{C}$ near the Philippines and smaller anomalies to the south and west); 3) a decrease in precipitation in the western equatorial Pacific accompanied by an increase near $10^{\circ}-15^{\circ} \mathrm{N}$, associated with the change in the latitudinal SST gradient in the western Pacific (with a small cold anomaly near the equator and a warm anomaly near $\left.30^{\circ} \mathrm{N}\right)$; 4) a decrease in precipitation over the Caribbean and southward shift of the ITCZ in the eastern Pacific associated with the change in the latitudinal SST gradient in the eastern Pacific and Caribbean (with cold anomalies near $15^{\circ} \mathrm{N}$ and a small warm anomaly near the equator); and 5) a decrease in precipitation from Brazil to tropical Africa accompanied by an increase over the western Indian Ocean, associated with the change in the longitudinal SST gradient between the equatorial Atlantic (with cold anomalies over $2^{\circ} \mathrm{C}$ ) and the western Indian (with anomalies close to zero) Oceans. One may assume that the 500-mb height anomalies result from the effect of the tropical convection anomalies on the generation and propagation of Rossby waves in the subtropics and midlatitudes, as occurs, for example, during ENSO. In the appendix, we show that the convection anomalies in the NH Tropics (features 2-5 described above) appear to account for most of the $\mathrm{NH}$ winter midlatitude circulation anomaly due to the 

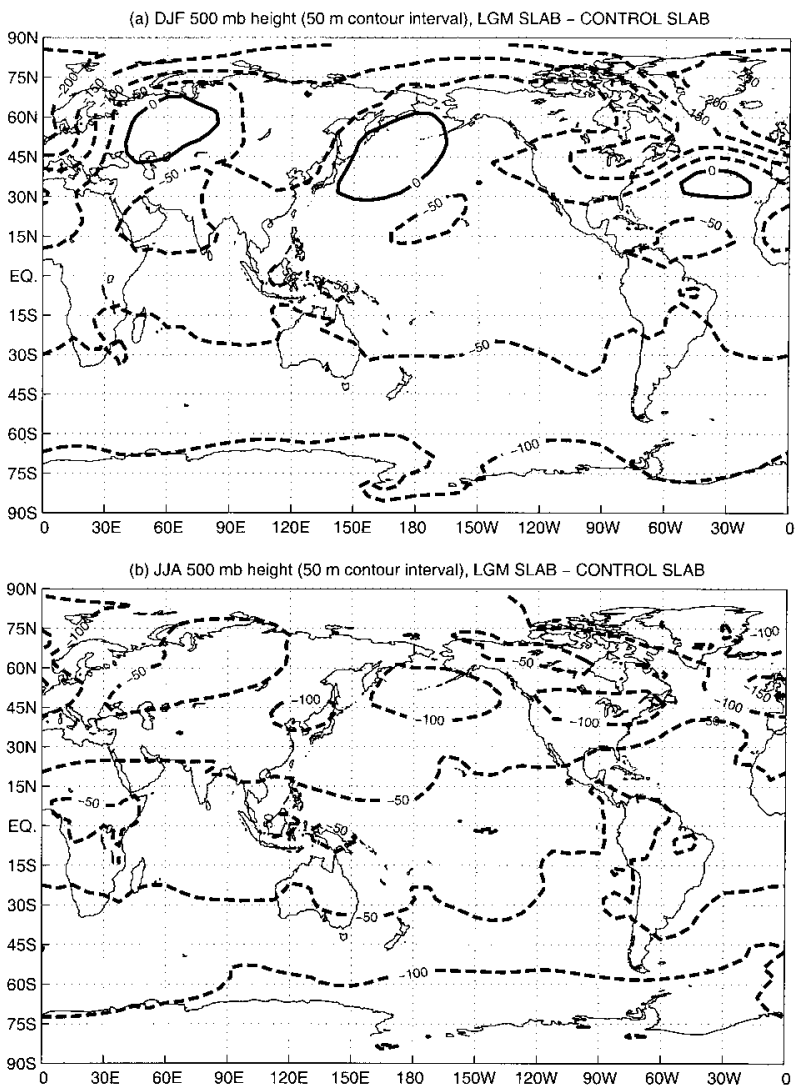

FIG. 5. As in Fig. 3, but for the difference in 500-mb geopotential height between CCM3 experiments LGM SLAB and CONTROL SLAB.

CLIMAP tropical SSTs and discuss the mechanisms by which they may be affecting the midlatitude circulation.

When SST is calculated using a mixed layer ocean model coupled to the CCM3, results are obtained that are more similar to the results of previous modeling studies using mixed layer ocean models coupled to GCMs (Broccoli and Manabe 1987; Dong and Valdes 1998). Experiments LGM SLAB and CONTROL SLAB are forced by ice sheet topography, greenhouse gas concentrations, and insolation representative of the LGM and present, respectively. The 500-mb geopotential height differences shown in Fig. 5 show no deep wintertime low anomaly over the North Pacific, and the precipitation differences shown in Fig. 6 are smaller and more spatially homogeneous. These features may be linked to the difference between the calculated SST changes at the LGM, shown in Fig. 7, and the prescribed SST changes (i.e., CLIMAP minus present), shown in Fig. 1. The calculated cooling in the Tropics is more uniform, approximately $3^{\circ}-4^{\circ} \mathrm{C}$ (see Fig. 2), so a general decrease in tropical precipitation occurs without the complex spatial patterns (cf. Fig. 6 to Fig. 4) that will be shown to excite a large midlatitude circulation response.

In order to remove the difference between the sim-

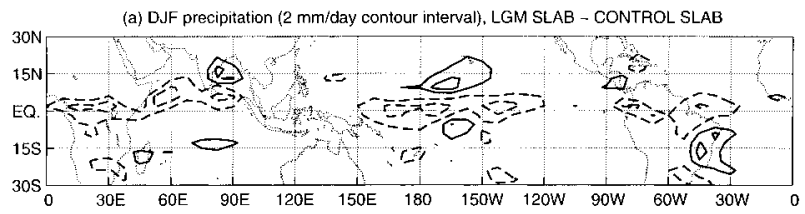

(b) JJA precipitation (2 mm/day contour interval), LGM SLAB - CONTROL SLAB

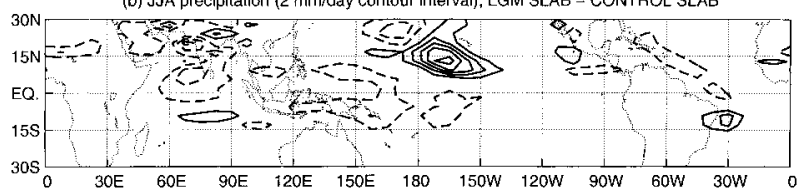

FIG. 6. As in Fig. 4, but for the difference in precipitation between CCM3 experiments LGM SLAB and CONTROL SLAB.

ulations of LGM and present-day climate due to changes in prescribed tropical SST, we performed experiment LGM Y2KSST with all LGM boundary conditions except for present-day SSTs prescribed between $30^{\circ} \mathrm{S}$ and $30^{\circ} \mathrm{N}$. The difference between experiments LGM Y2KSST and CONTROL is thus due to all of the LGM boundary conditions except for tropical SST. Hence, the difference between Fig. 3 and Fig. 8 illustrates the importance of the changes in tropical SST to the simulated LGM circulation changes. The difference in $500-\mathrm{mb}$
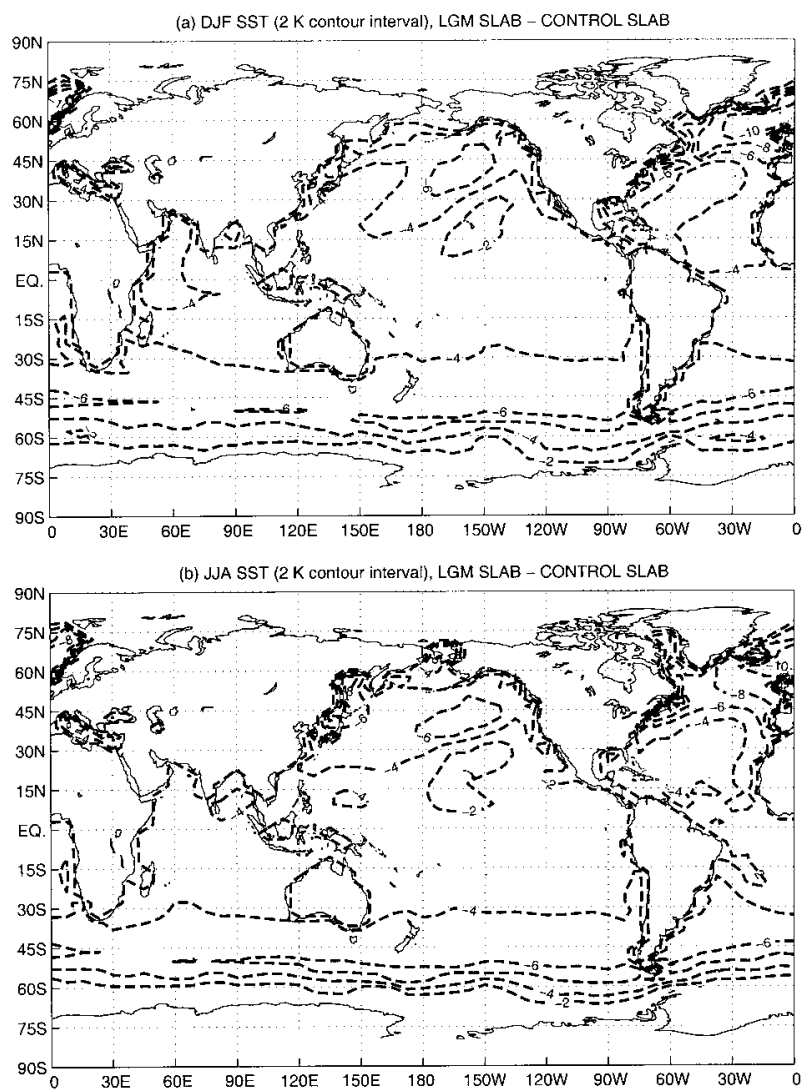

FIG. 7. Difference in SST between CCM3 experiments LGM SLAB and CONTROL SLAB in two seasons: (a) DJF and (b) JJA. The contour interval is $2^{\circ} \mathrm{C}$ with dashed lines indicating negative contours. 


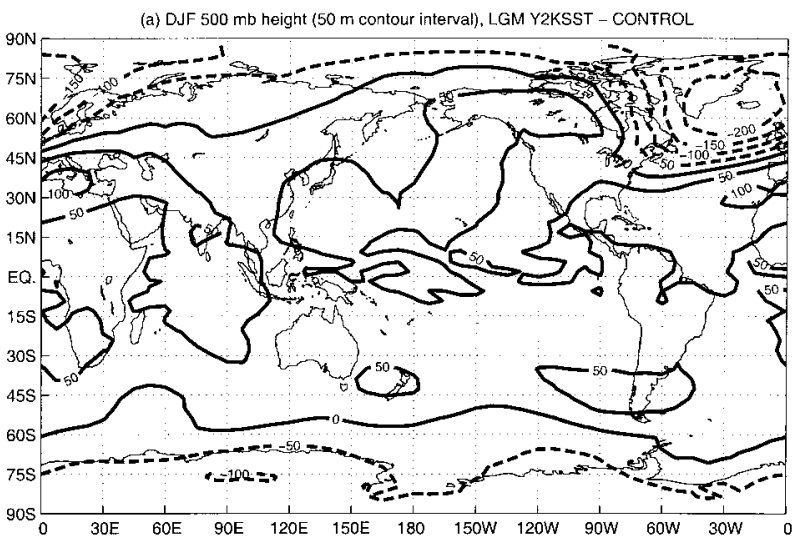

(b) JJA $500 \mathrm{mb}$ height (50 m contour interval), LGM Y2KSST - CONTROL

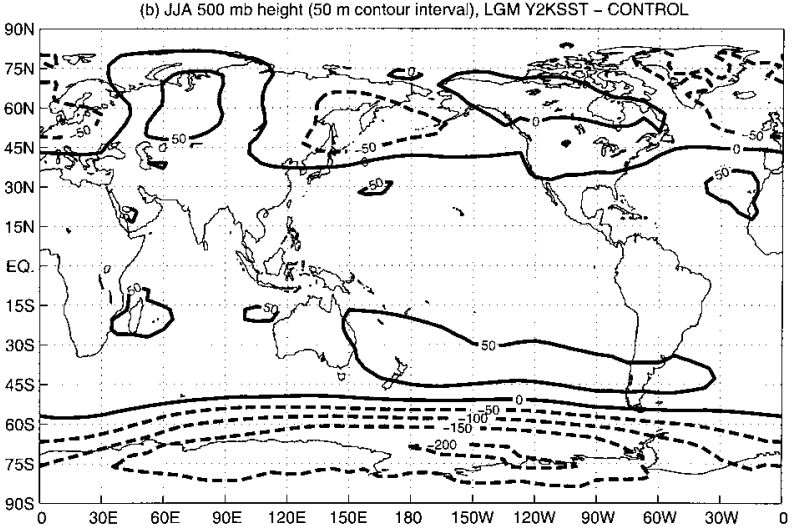

FIG. 8. As in Fig. 3, but for the difference in 500-mb geopotential height between CCM3 experiments LGM Y2KSST and CONTROL.

geopotential height shown in Fig. 8 lacks the deep low over the North Pacific seen in Fig. 3, and has a high over North America that is weaker and shifted to the west. The location of the weak high is on the upstream side of the Laurentide ice sheet, the expected location of a ridge forced by such a large topographical feature. These calculations demonstrate that differences between the CLIMAP reconstruction and present-day SST in the Tropics greatly affect the modeled atmospheric circulation at the LGM on a global scale.

The effect of the specified change in tropical SSTs on the LGM climate is more directly shown in the difference between experiments LGM CLIMAPSST and LGM Y2KSST that have identical boundary conditions other than the SST between $40^{\circ} \mathrm{S}$ and $40^{\circ} \mathrm{N}$. The difference in precipitation shown in Fig. 9 is nearly identical to the total difference between LGM CLIMAPSST and CONTROL shown in Fig. 4, so the tropical precipitation changes can be explained almost entirely by changes in prescribed tropical SST. The difference in 500-mb geopotential height shown in Fig. 10 shows a low over the North Pacific even deeper than that in Fig. 3 , along with a high over North America of comparable magnitude to that in Fig. 3. Hence, much of the geopotential height difference over the North Pacific and North America appears to be linked to the changes in

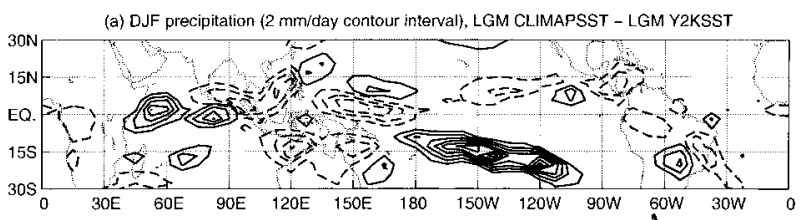
(b) JJA precipitation (2 $\mathrm{mm}$ /day contour interval), LGM CLIMAPSST - LGM Y2KSST

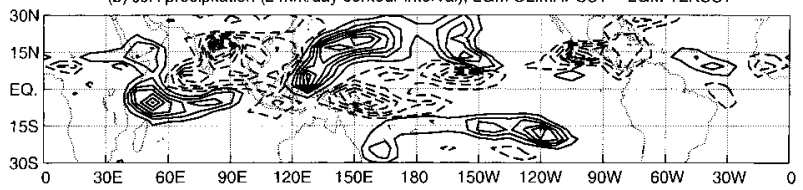

FIG. 9. As in Fig. 4, but for the difference in precipitation between CCM3 experiments LGM CLIMAPSST and LGM Y2KSST.

tropical convection induced by the change in tropical SST patterns between the CLIMAP reconstruction and present-day SSTs.

In order to assess the possible impact of the prescribed tropical SST change on the continental ice sheets, we examined the difference in reference height $(2 \mathrm{~m})$ temperature between experiments LGM CLIMAPSST and LGM Y2KSST, shown in Fig. 11. The modeled DJF warming over the Laurentide ice sheet and DJF cooling over the Fennoscandian ice sheet both exceed $8^{\circ} \mathrm{C}$. The
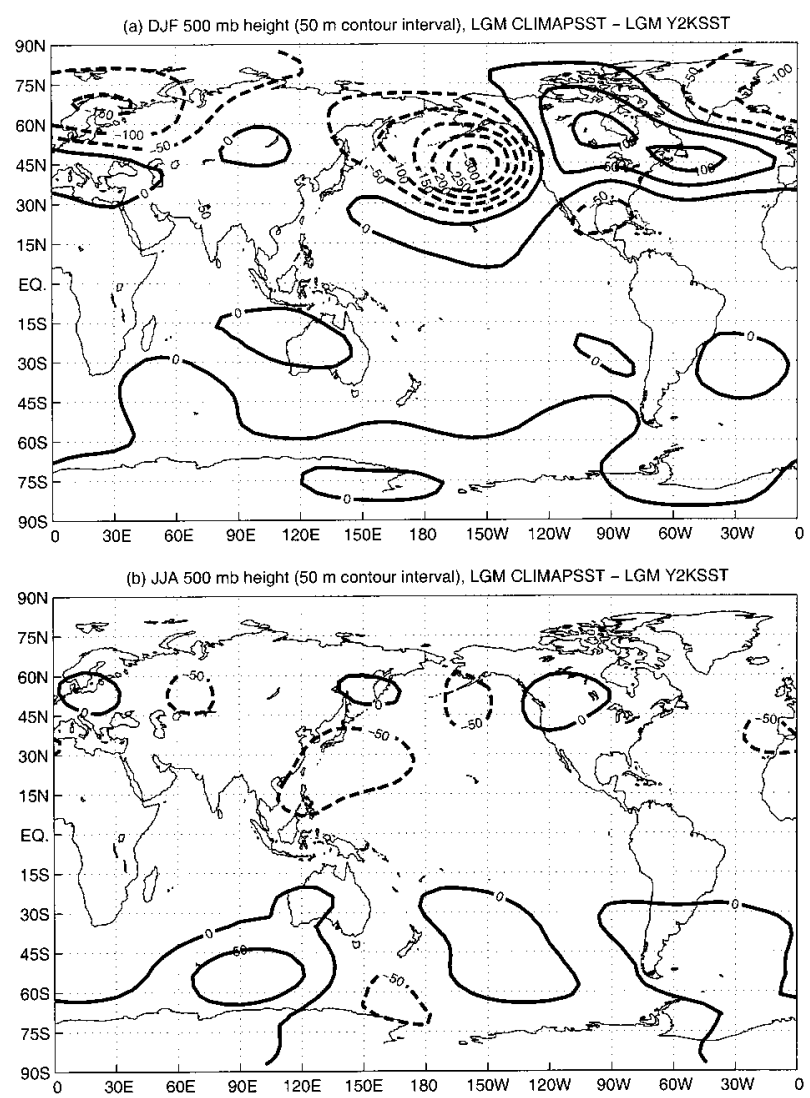

FIG. 10. As in Fig. 3, but for the difference in 500-mb geopotential height between CCM3 experiments LGM CLIMAPSST and LGM Y2KSST. 


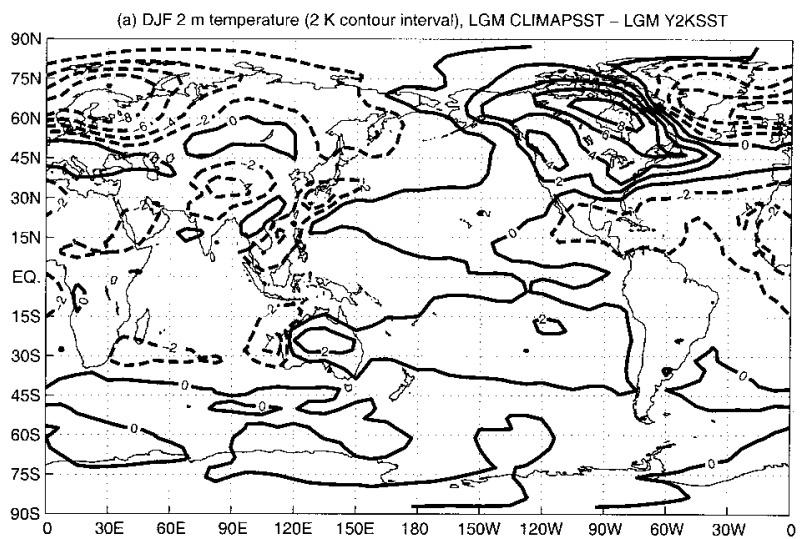

(b) JJA $2 \mathrm{~m}$ temperature (2 $\mathrm{K}$ contour interval), LGM CLIMAPSST - LGM Y2KSST

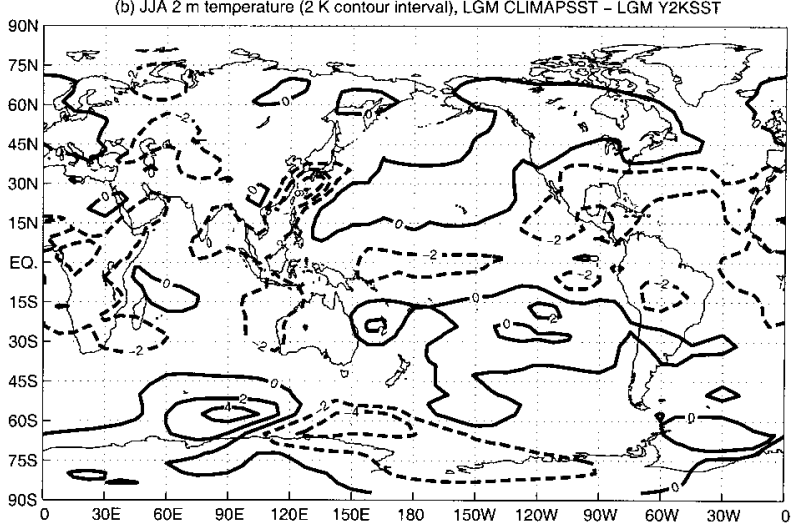

FIG. 11. Difference in reference height $(2 \mathrm{~m})$ temperature between CCM3 experiments LGM CLIMAPSST and LGM Y2KSST in two seasons: (a) DJF and (b) JJA. The contour interval is $2^{\circ} \mathrm{C}$, with dashed lines indicating negative contours.

Laurentide warming occurs as a result of southerly flow upwind of the ice sheet associated with the anomalous low over the North Pacific, while the Fennoscandian cooling is a result of the northerly flow upwind of the ice sheet associated with the anomalous low over the North Atlantic and northern Europe. We used the positive degree day formalism (Huybrechts and T'siobbel 1995), with the same parameters used in the ice sheet model of Tarasov and Peltier (1997), to calculate the snow- and ice melt in the LGM CLIMAPSST and LGM Y2KSST experiments, assuming that there is an infinite amount of ice available to melt in grid boxes where an ice sheet is present. The difference in annually averaged mass balance (snowfall - melt) for the NH ice sheets between runs LGM CLIMAPSST and LGM Y2KSST is shown in Fig. 12. Note that the largest changes occur along the southern margins of the ice sheets, where melting is important; the negative mass balance anomaly reaches $1000 \mathrm{~mm} \mathrm{yr}^{-1}$ (liquid water equivalent) at the southern margin of the Laurentide and the positive mass balance anomaly reaches $800 \mathrm{~mm} \mathrm{yr}^{-1}$ at the southern margin of the Fennoscandian. This occurs despite the small temperature anomalies over the ice sheets during the summer, when melting is most important; it turns
Annual ice mass balance (200 mm/yr contour interval), LGM CLIMAPSST - LGM Y2KSST

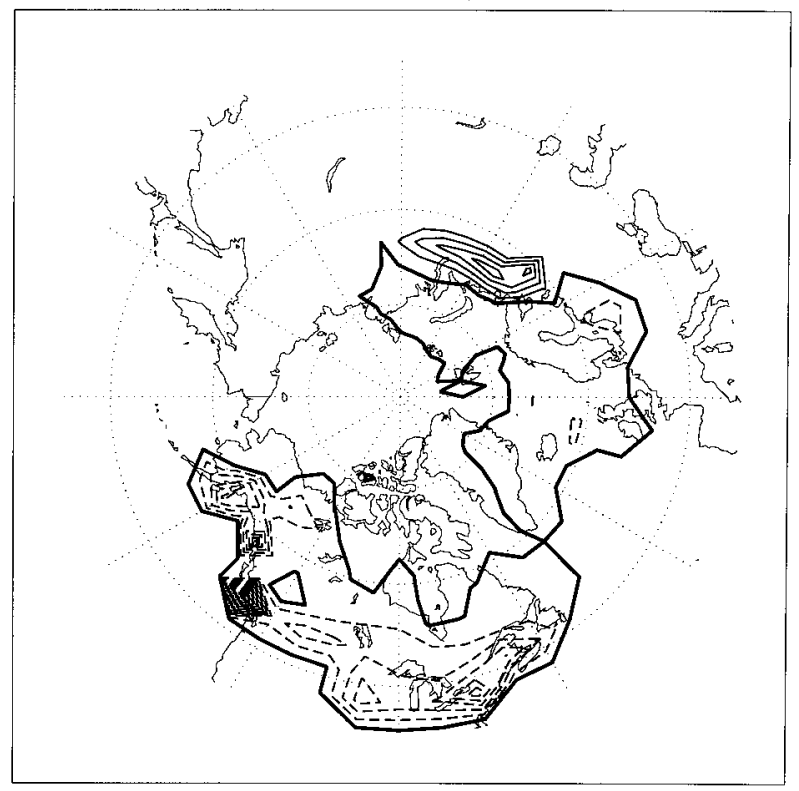

FIG. 12. The difference in annual mass balance (snowfall - melt) between CCM3 experiments LGM CLIMAPSST and LGM Y2KSST. The contour interval is $200 \mathrm{~mm} \mathrm{yr}^{-1}$ (liquid water equivalent) with dashed lines indicating negative contours and the zero contour emphasized with a thick solid line.

out that the changes in melting due to the relatively large temperature anomalies at the southern margins of the ice sheets in spring (not shown) contribute as much to the mass balance anomalies as changes in summer melting. Thus, while the effect of the winter warming (cooling) is to increase (decrease) snowfall over the Laurentide (Fennoscandian) ice sheet, the mass balance changes are dominated by the increased (decreased) melting due to the warming (cooling) over the Laurentide (Fennoscandian) ice sheet during spring and summer. Hence, differences in the patterns of tropical SST can result in substantial changes in the net mass balance of the LGM ice sheets.

Since one of the main criticisms of the CLIMAP reconstruction of LGM SST is that reconstructed tropical SSTs may be too warm, we also performed the experiment LGM CLIMAPSST COOL that used the same SSTs prescribed in LGM CLIMAPSST, but uniformly cooled by $3^{\circ} \mathrm{C}$ in the deep Tropics. The difference between LGM CLIMAPSST COOL and LGM CLIMAPSST is thus due to a relatively uniform cooling of tropical SSTs; the gradients in the deep tropical SST in the CLIMAP reconstruction are preserved in the LGM CLIMAPSST COOL experiment. The difference in precipitation between these experiments shown in Fig. 13 mainly reflects a decrease in tropical convection due to the cooling of the Tropics, with some shifting of convection from the cooler oceans to the relatively warm nearby land areas. The resulting $500-\mathrm{mb}$ geopotential height difference, shown in Fig. 14, does show some changes in midlatitude circulation resulting from the 


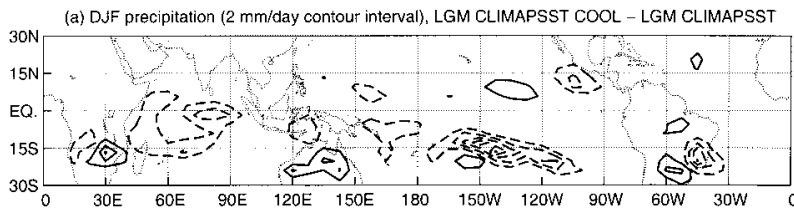

(b) JJA precipitation (2 mm/day contour interval), LGM CLIMAPSST COOL - LGM CLIMAPSST

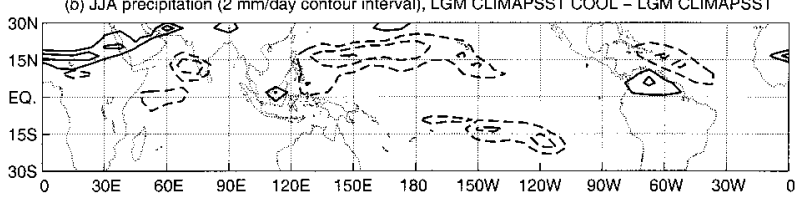

FIG. 13. As in Fig. 4, but for the difference in precipitation between CCM3 experiments LGM CLIMAPSST COOL and LGM CLIMAPSST.

decrease in tropical convection, but the changes seen are small compared those due to the CLIMAP tropical SST changes shown in Fig. 10. Not surprisingly, the differences in 2-m temperature due to the uniform cooling of the Tropics (not shown) are smaller as well. Hence, it is the changes in the tropical SST gradients that are most important for determining the midlatitude circulation during the LGM, while contributions from a uniform tropical cooling are small in comparison.
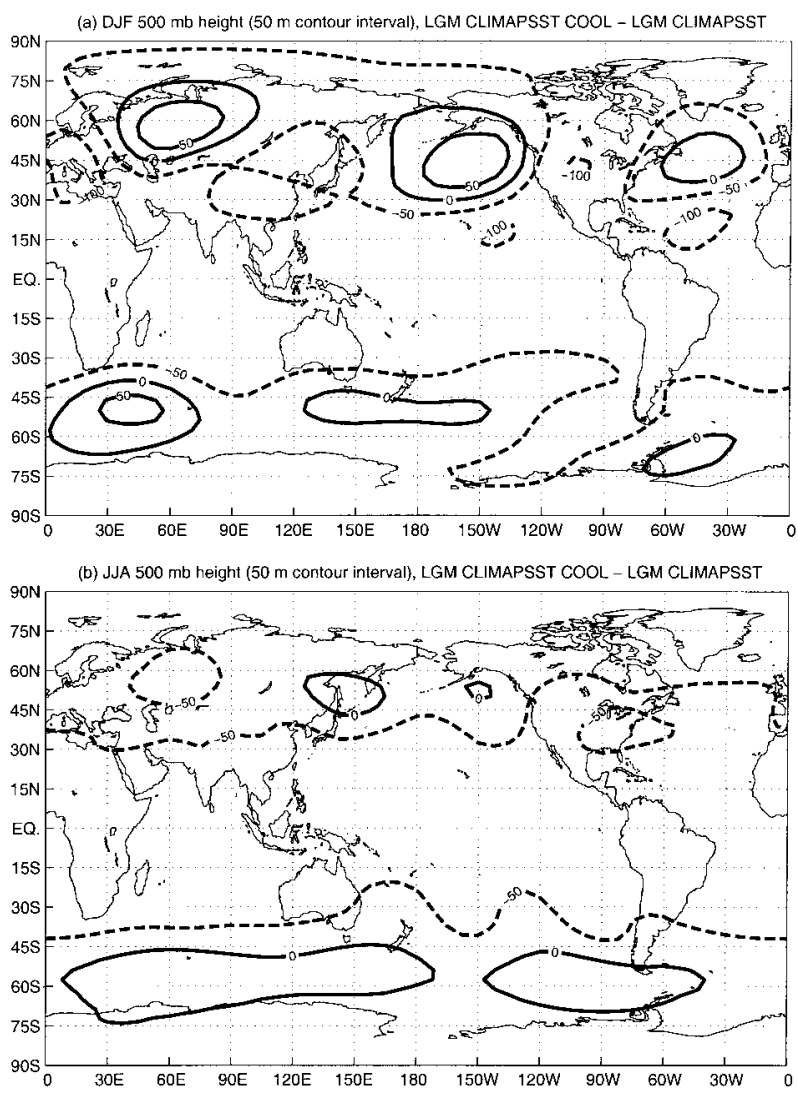

FIG. 14. As in Fig. 3, but for the difference in 500-mb geopotential height between CCM3 experiments LGM CLIMAPSST COOL and LGM CLIMAPSST.
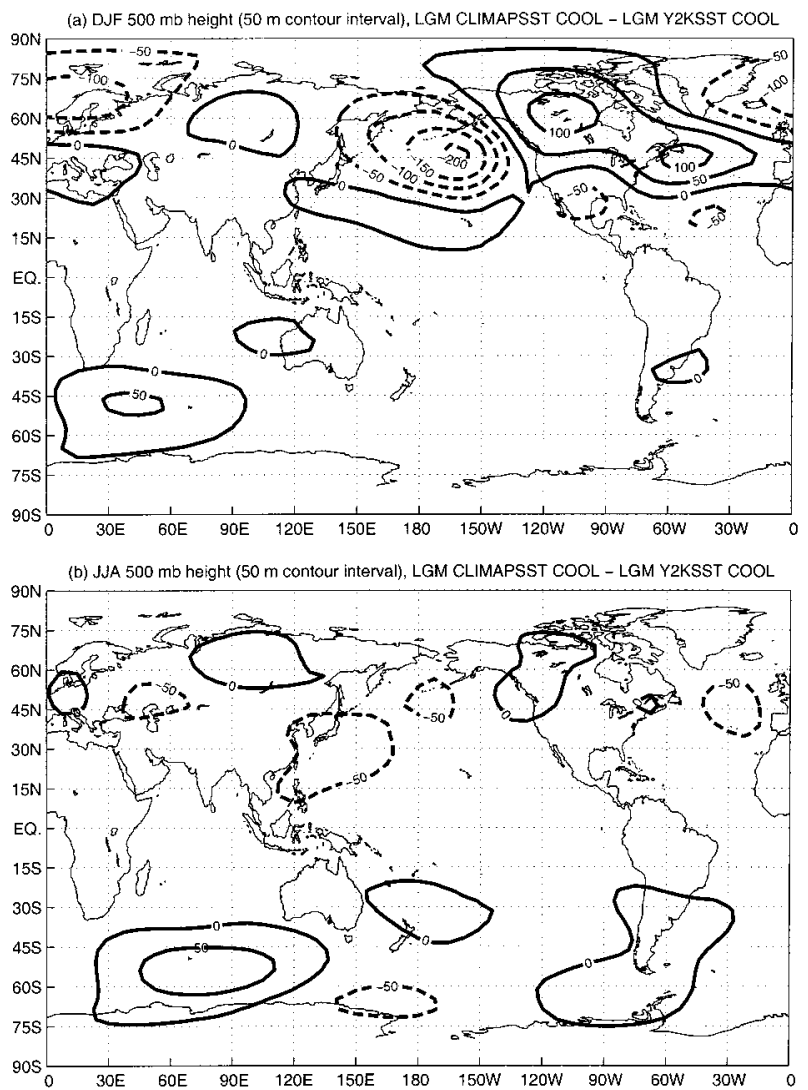

FIG. 15. As in Fig. 3, but for the difference in 500-mb geopotential height between CCM3 experiments LGM CLIMAPSST COOL and LGM Y2KSST COOL.

If it is likely that tropical SSTs at the LGM were $4^{\circ}-$ $5^{\circ} \mathrm{C}$ cooler than present, rather than the $1^{\circ}-2^{\circ} \mathrm{C}$ suggested by CLIMAP (1981), it is of interest to further explore the effects of changing tropical SST gradients in a world with cooler tropical SSTs. We performed the experiment LGM Y2KSST COOL that used the same SSTs prescribed in LGM Y2KSST, but again cooled by $3^{\circ} \mathrm{C}$ in the deep Tropics. The difference between LGM CLIMAPSST COOL and LGM Y2KSST COOL is thus due to the same changes in tropical SST gradients as the difference between LGM CLIMAPSST and LGM Y2KSST, but with SSTs uniformly cooler in the deep Tropics by $3^{\circ} \mathrm{C}$ in both experiments. The difference in $500-\mathrm{mb}$ geopotential height between LGM CLIMAPSST COOL and LGM Y2KSST COOL is shown in Fig. 15. As expected, the smaller tropical precipitation differences (not shown) result in smaller midlatitude circulation differences between these experiments. However, the midlatitude circulation response is nearly identical in its spatial pattern and approximately $75 \%$ of the magnitude of that shown in Fig. 10 for DJF, and the 2-m temperature differences (not shown) are also similar, if slightly smaller in magnitude. While we expect that the effect of tropical SST gradients on midlatitude circulation would be slightly smaller in a world 
(a) DJF $500 \mathrm{mb}$ height (50 $\mathrm{m}$ contour interval), LGM Y2KSST - LGM Y2KSST FLAT

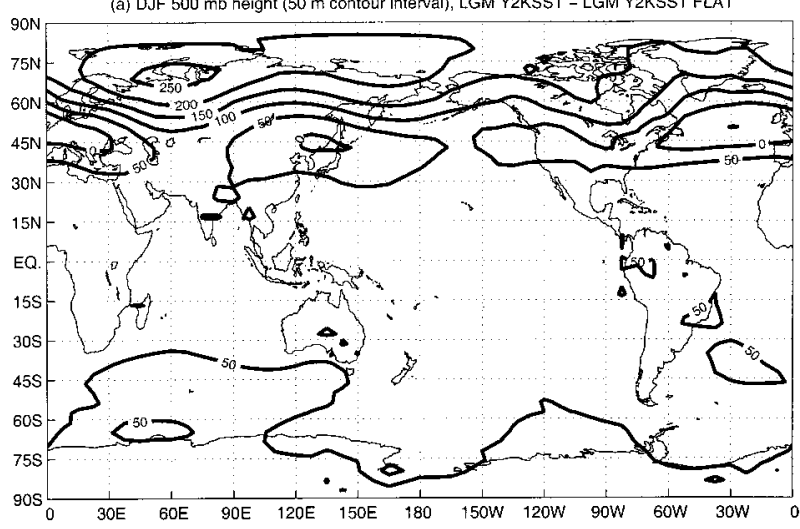

(b) JJA $500 \mathrm{mb}$ height (50 $\mathrm{m}$ contour interval), LGM Y2KSST - LGM Y2KSST FLAT

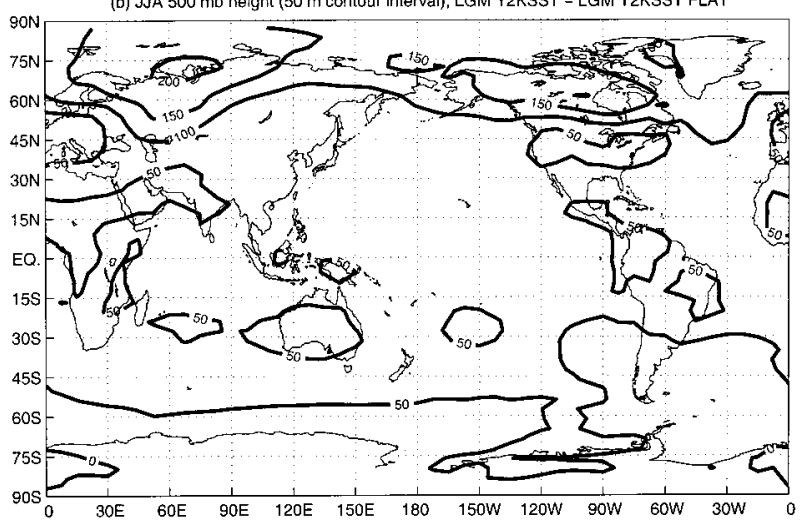

FIG. 16. As in Fig. 3, but for the difference in 500-mb geopotential height between CCM3 experiments LGM Y2KSST and LGM Y2KSST FLAT.

with uniformly cooler tropical SSTs, these experiments show that tropical SST gradients are still the dominant contributor to the midlatitude circulation changes at the LGM.

The work of Roe (1999) showed that the stationary waves forced by ice sheet topography can significantly affect the evolution and shape of the ice sheets, so one might ask how the magnitude of the circulation changes due to tropical SST gradients compare to those caused by ice sheet topography. To calculate the latter, we performed experiment LGM Y2KSST FLAT, with identical boundary conditions to LGM Y2KSST except that ice sheet elevation is reduced to that of present-day topography. Thus, the difference between the runs is solely due to the elevation of the ice sheets. The $500-\mathrm{mb}$ geopotential height difference between LGM Y2KSST and LGM Y2KSST FLAT is shown in Fig. 16. Near the Laurentide ice sheet in DJF, we see a weak anomalous low downstream of the ice sheet and an anomalous high upstream of the ice sheet, which appears somewhat as a continuation of the anomalous high centered over the Fennoscandian ice sheet. This is similar to the $500-\mathrm{mb}$ geopotential height pattern due to ice sheet topography found by Rind (1987), although that study also found an anomalous low downstream of the Fennoscandian ice sheet. The lack of an upstream high-downstream low pattern over the Fennoscandian ice sheet in our study probably results from the lower thickness of the Fennoscandian ice sheet (which is spectrally smoothed to less than $1500 \mathrm{~m}$ in our model) in the Peltier (1994) reconstruction when compared to its thickness of over $2000 \mathrm{~m}$ in the CLIMAP (1981) used by Rind (1987); in addition, the Peltier (1994) reconstruction of the Laurentide ice sheet is spectrally smoothed to just over 2000-m thick in our model, while its thickness exceeds $3000 \mathrm{~m}$ in the CLIMAP (1981) reconstruction. We find a maximum peak-to-trough amplitude of approximately $300 \mathrm{~m}$ in the 500-mb geopotential height difference due to ice sheet topography, similar to the peak-to-trough amplitude of approximately $250 \mathrm{~m}$ found by Rind (1987) despite the smaller ice sheets used in our experiments. ${ }^{1}$ In comparison, the difference in $500-\mathrm{mb}$ geopotential height due to CLIMAP tropical SSTs shown in Fig. 10 has a maximum peak-to-trough amplitude of over $400 \mathrm{~m}$. Hence, the effects of tropical SST gradients on the atmospheric circulation of the LGM are potentially at least as important as the effects of ice sheet topography. The physical mechanisms by which the tropical SST changes are teleconnected to the extratropics are discussed in the appendix.

\section{Discussion}

\section{a. Robustness of our results}

One question that arises is whether the changes in tropical convection and the accompanying anomalies in $\mathrm{NH}$ midlatitude winter circulation are robust responses to the CLIMAP SST reconstruction or model-dependent features. Of the three previous studies of LGM climate using prescribed SSTs surveyed in section 1, Hall et al. (1996) find tropical precipitation and 500-mb geopotential height changes that most closely match those produced by the current study. For instance, both studies agree on all five major features in the difference in DJF tropical precipitation described in section 3. Hall et al. (1996) also find the deep low anomalies over the North Pacific and North Atlantic found in the present study, although their high over North America does not appear as pronounced as that found in our experiments.

Our results are also similar, though less so, to those

\footnotetext{
${ }^{1}$ A run was performed just like LGM Y2KSST but with the taller CLIMAP (1981) ice sheets. The difference in 500-mb height between this run (called LGM Y2KSST TALL) and LGM Y2KSST FLAT had a peak-to-trough amplitude of over $600 \mathrm{~m}$ near the Laurentide ice sheet. This is over twice as large as the response to the elevation of the CLIMAP (1981) ice sheets in Rind (1987), even though the ice sheet topography in our experiments has been spectrally smoothed; the smaller response in his model could be due to its coarser resolution. While there is a consensus that the ice sheets were lower than estimated by CLIMAP (1981), we mention our results to indicate the maximum plausible contribution of the ice sheet elevation to the circulation anomalies at the LGM.
} 
of Joussaume (1993). The February tropical precipitation changes of Joussaume (1993) agree fairly well with our DJF precipitation changes in features 3 and 5 described in section 3 , as well as parts of features 1 (the increase in the SPCZ) and 2 (the increase across the Indian Ocean), but Joussaume (1993) finds no clear change in the ITCZ in the eastern Pacific. Nonetheless, enough of the important changes in tropical convection have been captured in order to produce a similar lowhigh-low pattern in the difference in 500-mb geopotential height over the North Pacific, North America, and the North Atlantic, although the pattern is shifted slightly to the east compared to ours.

The results of Rind (1987) also bear some resemblance to ours, although the coarse resolution $\left(8^{\circ}\right.$ lat by $10^{\circ}$ long) used in his simulations makes the identification of some features difficult. The DJF tropical precipitation changes of Rind (1987) include features similar to features 2,3 , and 4 described in section 3 , as well as part of feature 5 (the increase over northeast Brazil), but feature 1 appears to be missing entirely. Nevertheless, enough of the important features appear to have been captured in order to produce a similar response in 500-mb geopotential height to that found in our study, although it is smaller $(300 \mathrm{~m}$ in peak-totrough amplitude) and shifted to the west compared to the 500-mb height pattern found in our study. While we cannot be certain that similar changes in $\mathrm{NH}$ winter midlatitude circulation were produced in these three previous studies for the same reasons that they were produced by our simulations, the similarity between the LGM tropical precipitation and 500-mb geopotential height anomalies produced by all of these studies is encouraging.

\section{b. Implications}

The key role of tropical convection in forcing midlatitude circulation anomalies during $\mathrm{NH}$ winter has been illustrated in many studies of ENSO (e.g., Simmons et al. 1983; Zhang et al. 1997; Trenberth et al. 1998), so it should come as no surprise that tropical convection is important in determining midlatitude circulation at the LGM as well. In addition, since tropical convection anomalies are forced more by changes in SST gradients than by changes in mean tropical SST, demonstrating that tropical SSTs were several degrees colder than reconstructed by CLIMAP is not sufficient to accurately simulate and understand the global atmospheric circulation at the LGM, particularly in the NH winter. If a coupled atmosphere-ocean model (e.g., Bush and Philander 1998) is used to simulate LGM climate, attention must be paid to the details of the tropical SST patterns produced by the ocean component, as the calculated SST gradients may have large effects on the global circulation produced by the atmospheric component.

This study also has implications for models of the evolution of the ice sheets during the glacial cycles. Some ice age models are beginning to incorporate the response of atmospheric circulation to ice sheet topography (e.g., Roe 1999), because the temperature and precipitation changes induced by the presence of the ice sheet can have significant effects on ice sheet evolution. A comparison of the effects of ice sheet topography (Fig. 16) and tropical SST (Fig. 10) on 500-mb geopotential height reveals that the potential effects of tropical SST gradients on midlatitude circulation are comparable in magnitude to, if not greater than, the effects of ice sheet topography. The results of this study also indicate that CLIMAP tropical SST patterns are responsible for large (approximately $1 \mathrm{~m} \mathrm{yr}^{-1}$ liquid water equivalent) changes in mass balance along the southern margins of the $\mathrm{NH}$ ice sheets (Fig. 12). If significant changes in tropical convection occurred during the glacial cycles, ice sheet modelers may have to find a way to incorporate an interactive ocean component before an accurate picture of the evolution of the ice sheets can be produced.

While we do not wish to claim that the modeled changes in LGM climate resulting from the CLIMAP reconstruction of tropical SST actually occurred, the results of this study indicate that the Tropics add an important layer of complexity not generally considered in paleoclimate studies. The potential effects of the Tropics on global climate must be taken into account, whether through another CLIMAP-like effort to reconstruct patterns of tropical SST or the inclusion of interactive dynamical tropical ocean and atmosphere components in models of ice age climate. The work of Mix et al. (1999) to produce a new LGM SST reconstruction for the tropical Atlantic and eastern equatorial Pacific using a transfer function method more appropriate for reconstructing tropical SSTs is an important step in this direction. The general agreement between the Mix et al. (1999) reconstruction and the tropical Atlantic SSTs produced in LGM simulations using both ocean-only and ocean models coupled to atmosphere models of varying complexity (Bigg et al. 1998; Weaver et al. 1998; Bush and Philander 1998) is encouraging, but these models produce quite different LGM SSTs in other regions, such as the tropical Pacific, which must be understood and compared with paleodata. Our study underscores the importance of extending the work of Mix et al. (1999) to produce a more reliable LGM SST reconstruction for the Tropics of all three ocean basins. This is a difficult task, but the patterns of tropical SST must be known in some detail before we can determine if the Tropics did, in fact, play an important role in shaping the climate of the ice age earth.

\section{Conclusions}

Simulations of the climate at the LGM have been carried out using the NCAR CCM3 with prescribed SSTs. The LGM ice sheet reconstruction of Peltier 
(1994) was used to determine topography and surface types, and LGM values of insolation and greenhouse gases were used.

The prescribed SSTs used were based on the reconstruction of CLIMAP (1981); from simulation to simulation we have made various changes to the tropical SSTs. When the tropical SSTs were changed from those reconstructed by CLIMAP to today's climatology, large changes in tropical convection occurred, which in turn are responsible for the lion's share of the changes in the modeled NH midlatitude winter circulation; the CLIMAP SST distribution in the deep Tropics forces deep low anomalies over the North Pacific and North Atlantic and a high anomaly over North America when compared to the run using present tropical SST. This is not surprising, since even subtle shifts in tropical convection associated with ENSO and the ENSO-like decadal modes are observed to cause similar changes in the midlatitude atmospheric circulation today (e.g., Garreaud and Battisti 1999).

These changes in NH midlatitude winter climate occur despite the fact that there is no large change in the mean tropical SST between the present and the CLIMAP reconstruction. In fact, the midlatitude circulation changes due to the difference in the SST pattern between the present and the CLIMAP reconstruction are greater than the changes due to a uniform tropical SST cooling of $3^{\circ} \mathrm{C}$. Thus, if we are interested in producing an accurate simulation of LGM climate, it may be more important to determine the correct pattern of tropical SSTs at the LGM than it is to determine the magnitude of the mean tropical SST change.

These results also raise the question of whether changes in the Tropics could have had an effect on the evolution of the ice sheets. For example, the CLIMAP tropical SSTs produce atmospheric circulation changes that result in a wintertime warming of $8^{\circ} \mathrm{C}$ over the Laurentide ice sheet and a wintertime cooling of $8^{\circ} \mathrm{C}$ over the Fennoscandian ice sheet when compared to the simulation with present tropical SSTs. Despite little change in summer temperatures, the changes in melting due to transition-season temperature differences produce large changes in the annually averaged mass balance along the southern margins of the ice sheets. The effect of tropical SST gradients on the evolution of the ice sheets warrants further investigation.

Regardless of the accuracy of the CLIMAP SST reconstruction, the results of these experiments demonstrate that changes in tropical SST cannot be ignored in the study of LGM climate any more than they can be ignored in the study of today's climate. Our results indicate that, in addition to the mean change in tropical SST, accurate reconstructions of the pattern of tropical SST must be accomplished if we hope to accurately simulate the climate of the LGM.

Acknowledgments. The authors are grateful for the insightful comments by Mike Wallace, David Rind, and an anonymous reviewer; their suggestions led to additional experiments that more clearly illuminated the subtle ways in which the global tropical SST changes influence the midlatitude circulation at the LGM. We also benefited from fruitful discussions of ice sheets and stationary waves with Gerard Roe and Eric DeWeaver. Finally, we would like to thank Marc Michelsen for his assistance in setting up the CCM3 to run on the workstations at UW. This work was supported by a grant from the NOAA Office of Global Programs, and one of the authors (JHY) was supported through much of this work by a National Science Foundation Graduate Fellowship.

\section{APPENDIX}

\section{Dissection of the Effect of Tropical SST Anomalies on the Midlatitude Circulation}

In order to determine which regions of CLIMAP SST anomalies make important contributions to the modeled change in NH winter midlatitude circulation, we performed a large number of additional experiments with LGM boundary conditions in which various subregions of the Tropics had SSTs changed back to their presentday values. In this appendix, we will describe the results of experiments in which the SSTs in regions $\mathrm{A}, \mathrm{B}, \mathrm{C}$, and D shown in Fig. A1 are changed to their presentday values; the SSTs are changed such that these regions have present-day SSTs within the solid rectangles shown in Fig. A1, with a linear blend between present and CLIMAP SSTs in the 10 degrees of latitude and longitude beyond these rectangles, shown by the dashed rectangles in Fig. A1. We will refer to experiments with some of these regions changed to present-day SSTs as "LGM Y2KSST" followed by the letters of the regions in which SSTs have been changed to their present values; for example, LGM Y2KSST ABC has CLIMAP SSTs everywhere except within regions $\mathrm{A}, \mathrm{B}$, and $\mathrm{C}$.

Figure A1 shows that the main features in the CLIMAP SST anomalies in the various regions are as follows. Region A contains large (up to $4{ }^{\circ} \mathrm{C}$ ) cold anomalies in the eastern part of the box between the Philippines and Southeast Asia, as well as smaller cold anomalies in the western part of the box in the Bay of Bengal. Region B contains the warm anomalies in the central Pacific, reaching a maximum in the northern part of the box (near $20^{\circ}-30^{\circ} \mathrm{N}$ ), with small cold anomalies along the equator in the southern and western parts of the box. Region $\mathrm{C}$ contains cold anomalies larger than $2{ }^{\circ} \mathrm{C}$ across most of the northern part of the box, from just west of southern Mexico to the Caribbean, while there are small warm anomalies along the equator in the southwestern part of the box. Region D contains only cold anomalies, with the largest cold anomalies in the eastern part of the box near the west coast of Africa.

We find that the combined effect of the CLIMAP SST anomalies in regions $\mathrm{A}, \mathrm{B}, \mathrm{C}$, and D shown in Fig. A1 


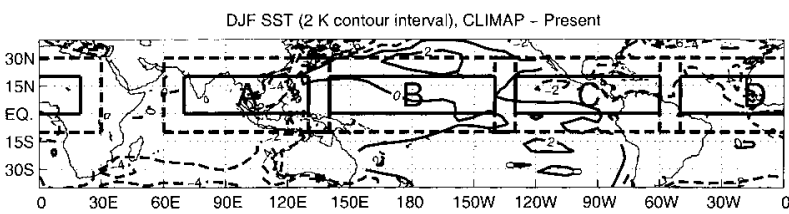

FIG. A1. The difference between the CLIMAP reconstruction of SST at the LGM and the present SST climatology in the Tropics during DJF. The contour interval is $2^{\circ} \mathrm{C}$ with dashed lines indicating negative contours. Regions of positive differences in SST are shaded. The superimposed bold rectangles indicate regions $\mathrm{A}, \mathrm{B}, \mathrm{C}$, and $\mathrm{D}$ of the CLIMAP tropical SST anomalies described in the text. The solid rectangles indicate the boundaries of the regions within which SSTs equal their present-day values, while the dashed rectangles indicate the boundaries of the regions outside of which SSTs equal their CLIMAP values. SSTs are linearly blended between CLIMAP and present-day values in the 10 degrees of lat and long between these rectangles.

accounts for most of the difference in DJF 500-mb geopotential height between experiments LGM CLIMAPSST and LGM Y2KSST (see Fig. 10a). The difference in DJF 500-mb geopotential height between LGM CLIMAPSST and LGM Y2KSST ABCD (in which the SSTs in all four boxes are changed to their present values) is shown in Fig. A2. The low anomaly over the North Pacific is $234 \mathrm{~m}$, compared to $305 \mathrm{~m}$ in Fig. 10a, and the high anomaly over eastern North America and the low anomaly over the Fennoscandian ice sheet are both of similar magnitudes in Figs. 10a and A2. The similarity between Figs. 10a and A2 suggest that the CLIMAP SST anomalies in the northern Tropics are responsible for the lion's share of the $\mathrm{NH}$ winter midlatitude circulation anomalies due to the CLIMAP tropical SSTs.

The differences in DJF 500-mb geopotential height between experiment LGM CLIMAPSST and the experiments in which regions $\mathrm{A}, \mathrm{B}, \mathrm{C}$, and $\mathrm{D}$ are separately changed to present-day SSTs are shown in Figs. A3a-d. Of the four regions, regions $\mathrm{B}$ and $\mathrm{C}$ appear to have the largest effect on the midlatitude circulation, although the CLIMAP SSTs in all four regions produce similar low-high-low patterns centered over the eastern North Pacific, eastern North America, and the Fennoscandian ice sheet (except that the response to region A is missing the last feature). The sum of the 500-mb height differences in these four plots is shown in Fig. A3e, which demonstrates that the separate effects of regions A through D do not add linearly to produce the effect of changing all four regions simultaneously (cf. Fig. A3e to Fig. A2); for example, the magnitudes of all three major features in 500-mb height are larger than in Fig. A2, and the center of the North Pacific low anomaly is shifted to the east compared to that in Fig. A2. This suggests some degree of nonlinearity either in the teleconnections to the midlatitudes or in the tropical response to the prescribed regional tropical SST anomalies.

As further confirmation of the nonlinearity in the response of midlatitude circulation to these four regions

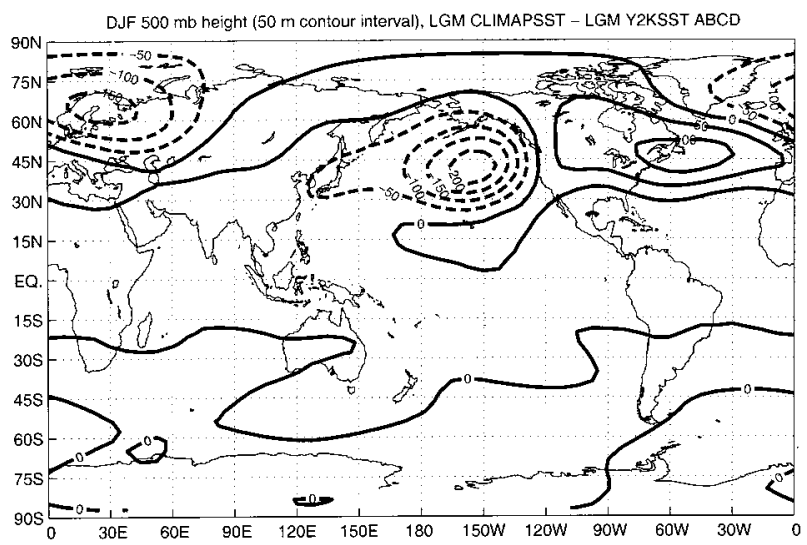

FIG. A2. Difference in DJF 500-mb geopotential height between CCM3 experiments LGM CLIMAPSST and LGM Y2KSST ABCD. The contour interval is $50 \mathrm{~m}$ with dashed lines indicating negative contours.

of CLIMAP SST anomalies, Figs. A4a-d show the change in $500-\mathrm{mb}$ height associated with each of the four regions when SSTs in two or three of the other regions have been changed from CLIMAP to presentday values. If the response were perfectly linear, Figs. A4a-d would be identical to Figs. A3a-d. In fact, the midlatitude response to the CLIMAP SST anomalies in each region is quite different when two or three of the other regions have been changed from CLIMAP to present-day values, and regions $\mathrm{A}$ and $\mathrm{D}$ now appear to produce the largest midlatitude circulation response. We will use the rest of this appendix to discuss mechanisms that may explain the midlatitude circulation anomalies shown in Figs. A3 and A4.

It is relatively easy to link the SST anomalies in regions A-D (see Fig. A1) with the DJF precipitation differences between experiment LGM CLIMAPSST and experiments LGM Y2KSST A-D shown in Figs. A5a-d. The cold SST anomalies near the coast of Southeast Asia in region A cause convection to move away from the coast and shift toward areas of less cold SST anomalies near the equator (Fig. A5a). The cold SST anomaly in the western equatorial Pacific in region $\mathrm{B}$ reduces convection just north of the equator in the western $\mathrm{Pa}$ cific and shifts it into the southern Tropics where SSTs have not been changed (Fig. A5b). The cold SST anomaly in the Caribbean in region $\mathrm{C}$ reduces convection there, while the change in the SST gradient near $110^{\circ} \mathrm{W}$ (with warm anomalies near the equator and cold anomalies near $15^{\circ} \mathrm{N}$ ) causes a southward shift and intensification of the ITCZ at the longitude (Fig. A5c). The cold SST anomalies in the tropical North Atlantic cause much of the convection in the Atlantic ITCZ to disappear and shift toward the warmer tropical Indian Ocean (see Fig. A5d). These changes in tropical convection are consistent with the explanations for precipitation features 2-5 described in section 3 . The changes in DJF precipitation due to the CLIMAP SST anomalies in regions $\mathrm{A}-\mathrm{D}$ when two or three of the other regions 


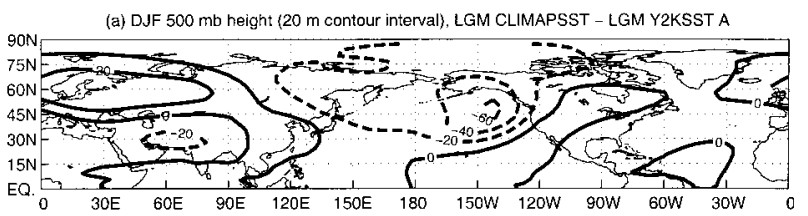

(b) D.JF $500 \mathrm{mb}$ height (20 $\mathrm{m}$ contour interval), LGM CLIMAPSST - LGM Y2KSST B

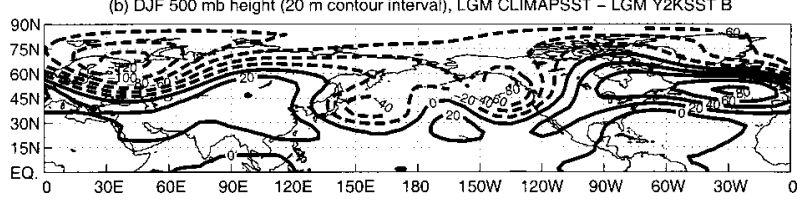

(c) DJF $500 \mathrm{mb}$ height (20 m contour interval), LGM CLIMAPSST - LGM Y2KSST C

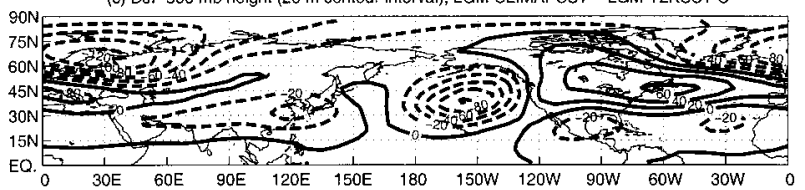

(d) DJF $500 \mathrm{mb}$ height (20 m contour interval), LGM CLIMAPSST - LGM Y2KSST D

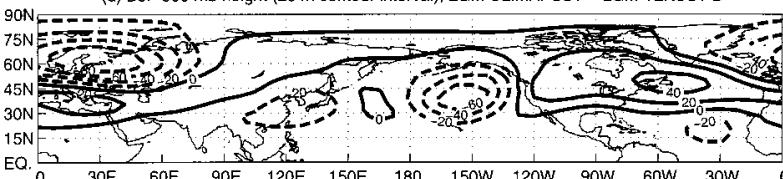

EQ.

(e) Sum of $500 \mathrm{mb}$ height differences in above 4 tigures $(50 \mathrm{~m}$ contour interval)

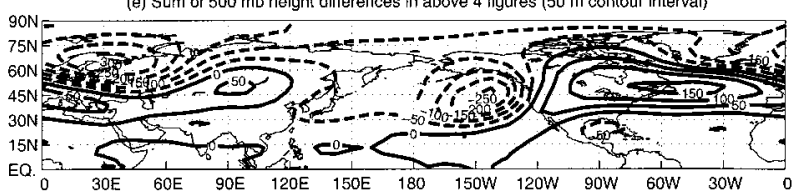

FIG. A3. Difference in DJF 500-mb geopotential height between CCM3 experiment LGM CLIMAPSST and these four experiments (a) LGM Y2KSST A, (b) LGM Y2KSST B, (c) LGM Y2KSST C, and (d) LGM Y2KSST D. The sum of the differences in (a)-(d) is shown in (e). The contour interval for (a)-(d) is $20 \mathrm{~m}$, and the contour interval for (e) is $50 \mathrm{~m}$ with dashed lines indicating negative contours

have already been changed to present-day SSTs, shown in Figs. A6a-d, are quite similar to those shown in Figs. A5a-d. Hence, tropical convection is not the source of the nonlinearity in the midlatitude response to the tropical SST anomalies.

In order to illustrate the circulation anomalies forced by the CLIMAP SST anomalies in regions A-D, we show the DJF 150-mb zonal wind differences in Figs. $\mathrm{A} 7$ and A8 and the DJF 150-mb meridional wind differences in Figs. A9 and A10 for these eight pairs of experiments. One feature shared by all eight pairs of experiments is the strong upper-level cyclonic (anticyclonic) circulation in the subtropics directly poleward of regions of large decrease (increase) in tropical convection. While many studies of ENSO have found similar responses of subtropical circulation to tropical convection anomalies (Trenberth et al. 1998), Held et al. (1989) use a baroclinic stationary wave model to demonstrate that this subtropical response is largely due to the effects of anomalous transients, rather than local Hadley circulation changes as previously assumed. In fact, the latitude of the subtropical circulation anomaly appears to be controlled, to some degree, by the position

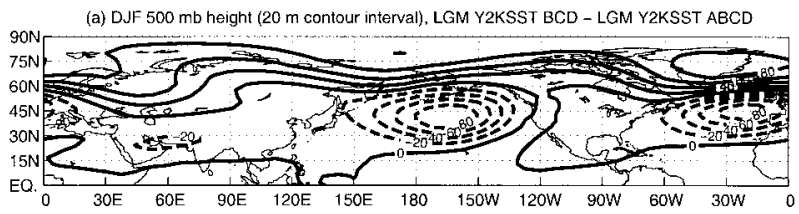

(b) DJF $500 \mathrm{mb}$ height (20 m contour interval), LGM Y2KSST CD - LGM Y2KSST BCD

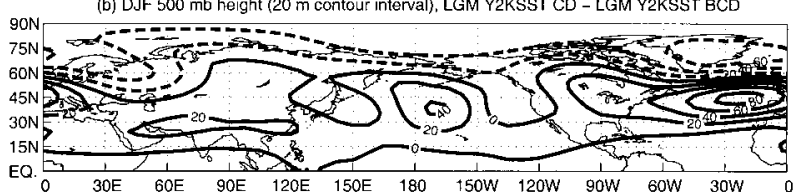

(c) DJF $500 \mathrm{mb}$ height (20 m contour interval), LGM Y2KSST AB - LGM Y2KSST ABC

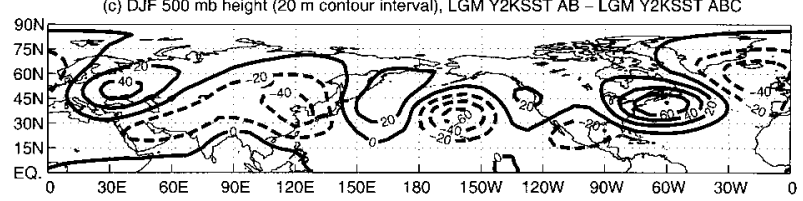

(d) DJF $500 \mathrm{mb}$ height (20 m contour interval), LGM Y2KSST ABC - LGM Y2KSST ABCD

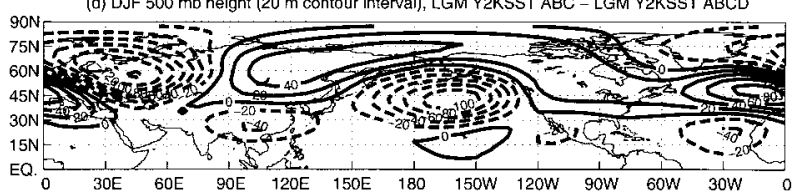

FIG. A4. Difference in DJF 500-mb geopotential height between these four pairs of CCM3 experiments: (a) LGM Y2KSST BCD LGM Y2KSST ABCD, (b) LGM Y2KSST CD - LGM Y2KSST BCD, (c) LGM Y2KSST AB - LGM Y2KSST ABC, and (d) LGM Y2KSST ABC - LGM Y2KSST ABCD. The contour interval for (a)-(d) is $20 \mathrm{~m}$ with dashed lines indicating negative contours.

of the subtropical jet. For example, the subtropical cyclonic anomaly over Arabia and India in Fig. A7a is centered near $30^{\circ} \mathrm{N}$, while the subtropical cyclonic anomaly east of Japan in Fig. A7b is centered between $35^{\circ}$ and $40^{\circ} \mathrm{N}$; both circulation anomalies are centered near the core of the local subtropical jet. However, the subtropical cyclonic anomalies in the Atlantic sector in Figs. A7c and A7d both lie south of the Atlantic jet, so our results do not indicate that the subtropical response always straddles the jet. Although we cannot elaborate on the link between the tropical convection anomalies and the subtropical response without significant additional work to investigate the effect of transients, the subtropical circulation anomalies shown here are consistent with the results of ENSO studies, and their proximity to the subtropical jets indicates that transients may well play a role in enhancing the subtropical circulation anomalies. We also note that, although we do not show it here, there is little or no subtropical circulation response to the tropical convection anomalies in the summer (Southern) Hemisphere, which supports the importance of winter hemisphere transients as well.

Another important mechanism is the effect of upperlevel zonal winds on Rossby wave propagation. Webster and Holton (1982) demonstrate that Rossby waves, which are normally prevented from propagating close to the equator by the upper-level easterlies in the Tropics, can propagate across the Tropics in regions of local 


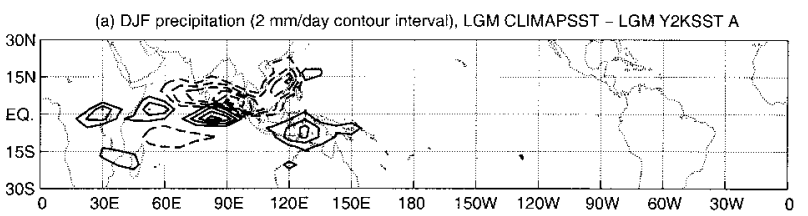

(b) DJF precipitation (2 mm/day contour interval), LGM CLIMAPSST - LGM Y2KSST B

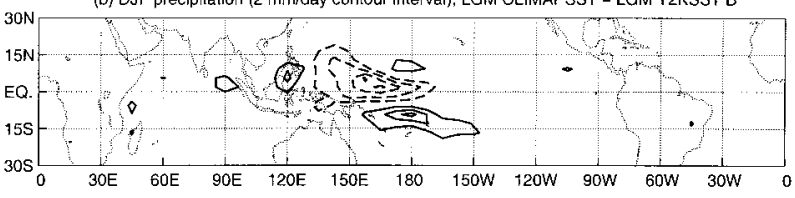

(c) DJF precipitation (2 $\mathrm{mm} /$ day contour interval), LGM CLIMAPSST - LGM YZKSST C

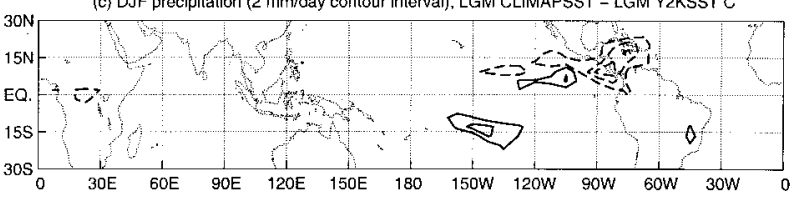

(d) DJF precipitation (2 $\mathrm{mm}$ /day contour interval), LGM CLIMAPSST - LGM Y2KSST D

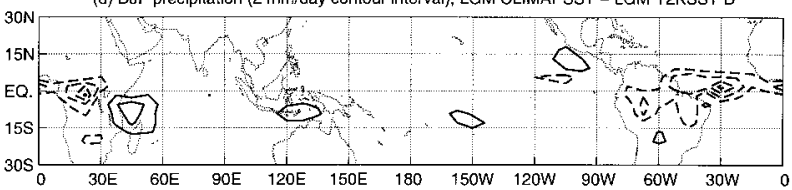

FIG. A5. Difference in DJF precipitation between CCM3 experiments LGM CLIMAPSST and these four experiments: (a) LGM Y2KSST A, (b) LGM Y2KSST B, (c) LGM Y2KSST C, and (d) LGM Y2KSST D. The contour interval for (a)-(d) is $2 \mathrm{~mm} \mathrm{day}^{-1}$ with dashed lines indicating negative contours and the zero contour omitted.

upper-level westerlies. Hence, changes in upper-level zonal winds in the Tropics will affect the ability of Rossby waves to propagate there; an easterly anomaly will tend to cause Rossby waves to break farther poleward, while a westerly anomaly will tend to cause Rossby waves to propagate farther equatorward before breaking. These effects will be more important in the tropical westerly "ducts" where Rossby waves are more likely to propagate equatorward. This mechanism is best illustrated by the response in DJF 150-mb zonal wind to the CLIMAP SST anomalies in region A, shown in Figs. A7a and A8a. The total zonal wind fields for experiments LGM CLIMAPSST and LGM Y2KSST BCD (Figs. A7e and A8e) show that one westerly duct is located in the eastern tropical Pacific southeast of the Pacific jet exit region, and the Pacific jet exit is located farther west in LGM Y2KSST BCD than in LGM CLIMAPSST. When the decrease in convection in region A modifies the Walker circulation to produce an upperlevel easterly anomaly stretching across the north tropical Pacific, this causes the Rossby waves propagating equatorward near the Pacific jet exit region to break farther poleward. This, in turn, produces a north-south dipole in zonal wind anomalies, with a westerly anomaly near $30^{\circ} \mathrm{N}$ and an easterly anomaly near $15^{\circ} \mathrm{N}$ (see Fig. A7a). Because the jet exit region is farther west in LGM Y2KSST BCD than in LGM CLIMAPSST, the zonal wind anomalies in the eastern Pacific in Fig. A8a are

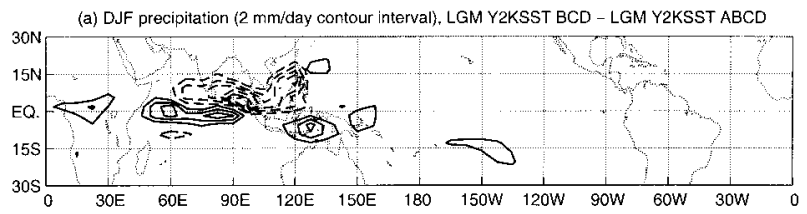

(b) DJF precipitation (2 mm/day contour interval), LGM Y2KSST CD - LGM Y2KSST BCD

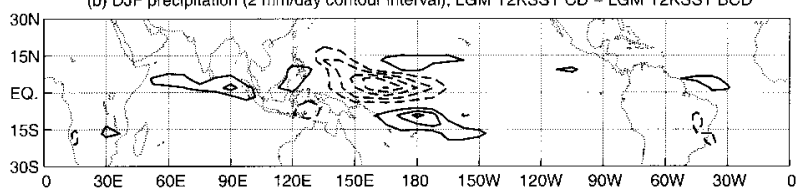

(c) DJJ precipitation (2 mm/day contour interval), LGM Y2KSST AB - LGM Y2KSST ABC

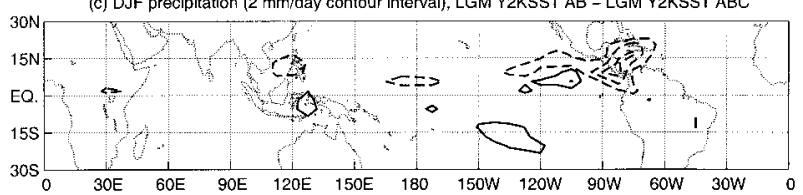

(d) DJF precipitation (2 mm/day contour interval), LGM Y2KSST ABC - LGM Y2KSST ABCD

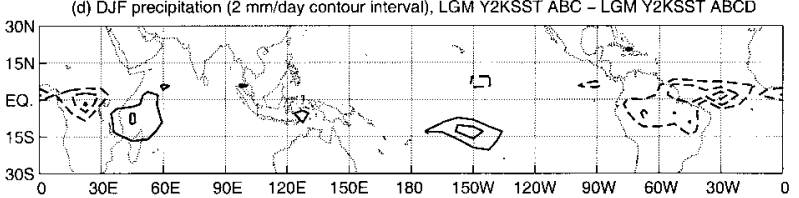

FIG. A6. Difference in DJF precipitation between these four pairs of CCM3 experiments: (a) LGM Y2KSST BCD - LGM Y2KSST ABCD, (b) LGM Y2KSST CD - LGM Y2KSST BCD, (c) LGM Y2KSST AB - LGM Y2KSST ABC, and (d) LGM Y2KSST ABC - LGM Y2KSST ABCD. The contour interval for (a)-(d) is $2 \mathrm{~mm}$ day $^{-1}$ with dashed lines indicating negative contours and the zero contour omitted.

farther west than those in Fig. A7a. The upper-level easterlies across the tropical Pacific in Figs. A7b and A8b, which are part of the rearrangement of the Walker circulation in response to the decrease in convection in the western tropical Pacific, have a similar effect on the propagation of Rossby waves in the Pacific jet exit region, although the wave propagating along the Pacific jet in both cases obscures the resulting dipole in zonal wind. The easterlies near the equator in the eastern $\mathrm{Pa}$ cific in Figs. A7c and A8c also appear to cause Rossby waves in the Pacific jet exit to break farther poleward, with a smaller response in zonal wind in Fig. A8c because the jet exit region is west of the easterly anomaly in this case. For region D, the upper-level westerly anomaly appears to have a larger effect on the propagation of Rossby waves equatorward of the Atlantic jet exit region in Fig. A8d than in Fig. A7d because the westerlies off the west coast of Africa are weaker in LGM Y2KSST ABC (not shown) than in LGM CLIMAPSST. This produces a subtropical circulation anomaly over the Atlantic in Fig. A4d that is larger and centered farther east than that in Fig. A3d.

The jet exit regions also appear to support a positive feedback between transient momentum fluxes and the mean flow. Held et al. (1989) show that the anomalous transients in the extended Pacific jet during the warm phase of ENSO tend to produce convergence of westerly momentum into the jet from both the poleward and 
(a) DJF $150 \mathrm{mb}$ zonal wind ( $2 \mathrm{~m} / \mathrm{s}$ contour interval), LGM CLIMAPSST - LGM Y2KSST A

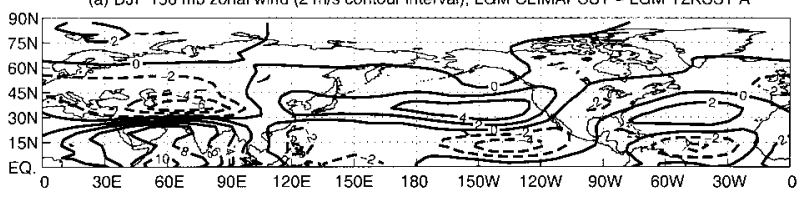

(b) DJF $150 \mathrm{mb}$ zonal wind (2 $\mathrm{m} / \mathrm{s}$ contour interval), LGM CLIMAPSST - LGM Y2KSST B

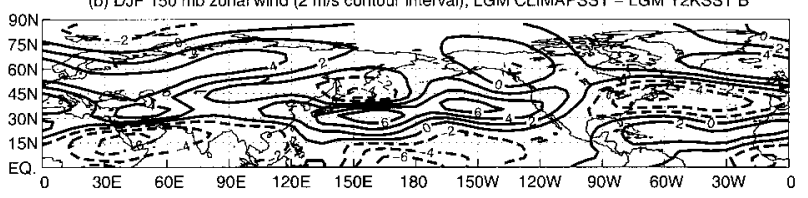

(c) D.JF $150 \mathrm{mb}$ zonal wind ( $2 \mathrm{~m} / \mathrm{s}$ contour interval), LGM CLIMAPSST - LGM Y2KSST C

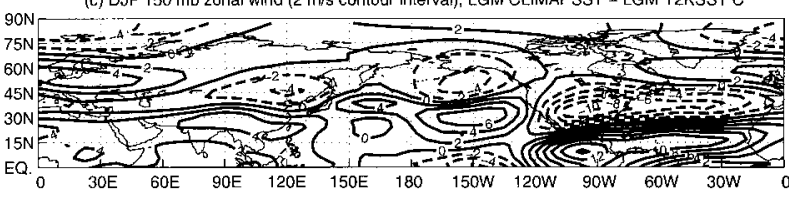

(d) DJF $150 \mathrm{mb}$ zonal wind ( $2 \mathrm{~m} / \mathrm{s}$ contour interval), LGM CLIMAPSST - LGM Y2KSST D

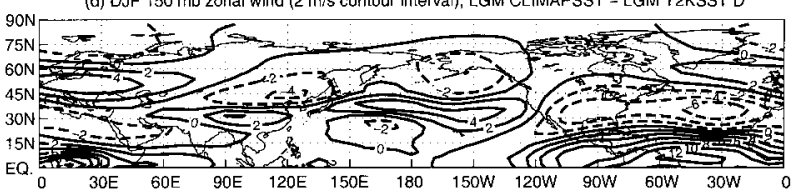

(e) DJF $150 \mathrm{mb}$ zonal wind ( $10 \mathrm{~m} / \mathrm{s}$ contour interval), LGM CLIMAPSST

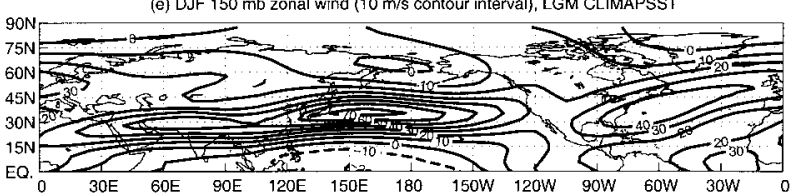

FIG. A7. Difference in DJF 150-mb zonal wind between CCM3 experiments LGM CLIMAPSST and these four experiments: (a) LGM Y2KSST A, (b) LGM Y2KSST B, (c) LGM Y2KSST C, and (d) LGM Y2KSST D. (e) The total DJF zonal wind field for CCM3 experiment LGM CLIMAPSST is shown. The contour interval for (a)-(d) is $2 \mathrm{~m} \mathrm{~s}^{-1}$, and the contour interval for (e) is $10 \mathrm{~m} \mathrm{~s}^{-1}$ with dashed lines indicating negative contours.

equatorward flanks, thus increasing the strength of the jet. As transient activity is largest within the jet, the resulting extension of the jet should produce yet more transient activity and momentum flux into the jet exit region. The source of dissipation that prevents this positive feedback from continuing indefinitely is unclear, but the enhancement of the circulation anomalies in the Pacific jet exit region in nearly all pairs of experiments provides evidence that this mechanism is at work. In Figs. A7 and A8, the westerly anomalies in the jet exit region are accompanied in all cases by easterly anomalies both poleward and equatorward of the jet exit. Figures A3c, A3d, and A4c also show that the waves propagating across the Pacific are enhanced at the jet exit, although part of this enhancement in Figs. A3c and $\mathrm{A} 4 \mathrm{c}$ is due to the modification of Rossby wave propagation by the easterlies equatorward of the jet exit.

We will venture further into the realm of speculation to discuss possible controls on the propagation of Rossby waves in our experiments. Various studies (e.g., Ambrizzi and Hoskins 1997) have demonstrated that Rossby waves tend to be guided along the subtropical jets,
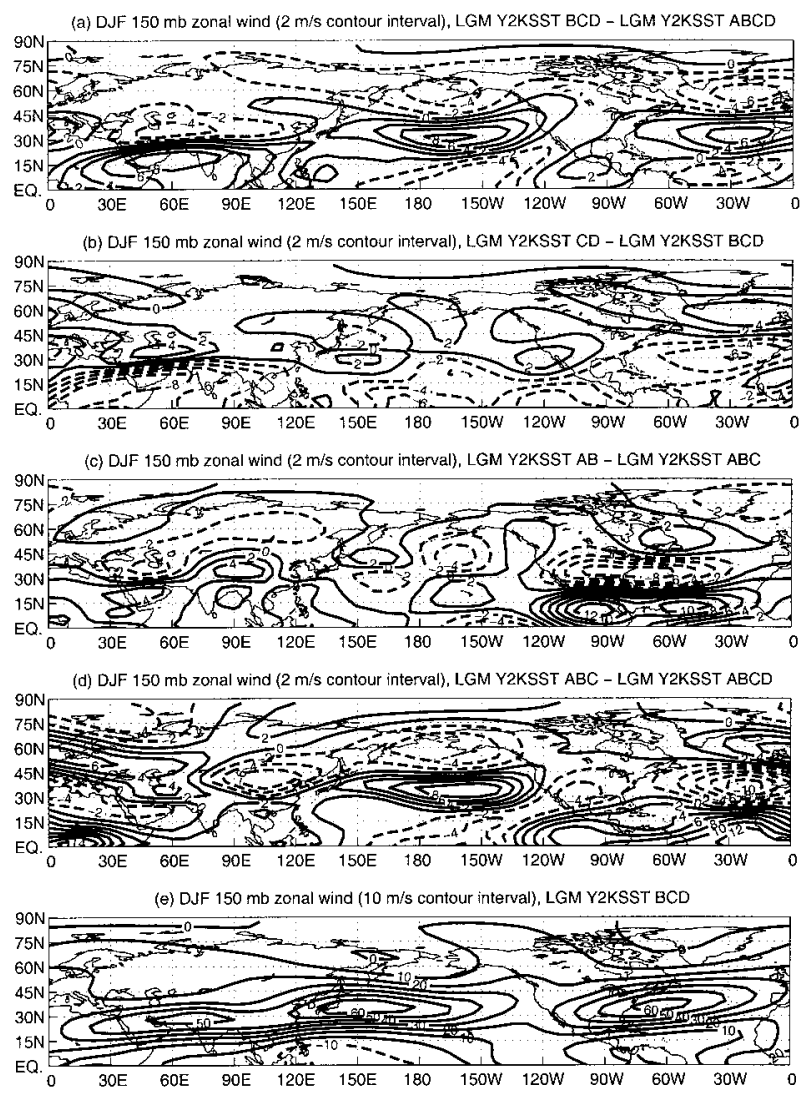

FIG. A8. Difference in DJF 150-mb zonal wind between these four pairs of CCM3 experiments: (a) LGM Y2KSST BCD - LGM Y2KSST ABCD, (b) LGM Y2KSST CD - LGM Y2KSST BCD, (c) LGM Y2KSST AB - LGM Y2KSST ABC, and (d) LGM Y2KSST ABC - LGM Y2KSST ABCD. (e) The total DJF zonal wind field for CCM3 experiment LGM Y2KSST BCD is shown. The contour interval for (a)-(d) is $2 \mathrm{~m} \mathrm{~s}^{-1}$, and the contour interval for panel (e) is $10 \mathrm{~m} \mathrm{~s}^{-1}$ with dashed lines indicating negative contours.

which are indicated in Figs. A9 and A10 by the shading of regions where the DJF $150-\mathrm{mb}$ zonal wind exceeds $30 \mathrm{~m} \mathrm{~s}^{-1}$. Such behavior is most easily seen in the meridional wind anomalies in Fig. A10c. The wave propagates eastward from the subtropical cyclonic anomaly associated with the decrease in precipitation in the Caribbean, following the northward tilt of the Atlantic jet (see shading in Fig. A10c). It then turns equatorward from the Atlantic jet exit near $60^{\circ} \mathrm{N}, 15^{\circ} \mathrm{E}$ and reaches the Arabian jet, which it follows directly eastward to the Pacific jet. Finally, it follows the Pacific jet eastward and turns slightly equatorward at the Pacific jet exit near $35^{\circ} \mathrm{N}, 130^{\circ} \mathrm{W}$ before reaching its source over Mexico. This mechanism is also important in the response to CLIMAP SST anomalies in region B. In Fig. A10b, the wave propagating along the Pacific jet starts its equatorward turn farther west (near $140^{\circ}$ instead of $120^{\circ} \mathrm{W}$ ) and equatorward (near $40^{\circ}$ instead of $50^{\circ} \mathrm{N}$ ) than the wave in Fig. A9b because of the shorter Pacific jet in LGM Y2KSST CD compared to LGM CLIMAPSST (cf. shading in Fig. A10b to that in Fig. 
(a) D.JF $150 \mathrm{mb}$ meridional wind (2 m/s contour interval), LGM CLIMAPSST - LGM Y2KSST A

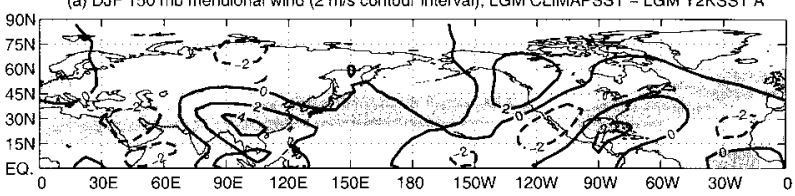

(b) DJF $150 \mathrm{mb}$ meridional wind ( $2 \mathrm{~m} / \mathrm{s}$ contour interval), LGM CLIMAPSST - LGM Y2KSST B

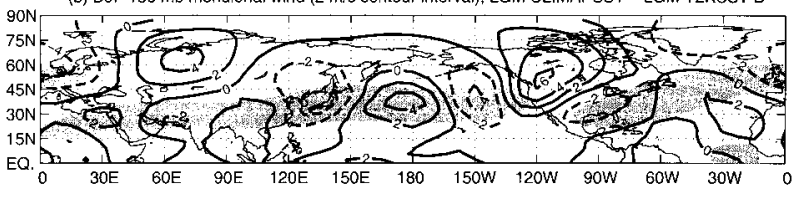

(c) DJF $150 \mathrm{mb}$ meridional wind (2 $\mathrm{m} / \mathrm{s}$ contour interval), LGM CLIMAPSST - LGM Y2KSST C

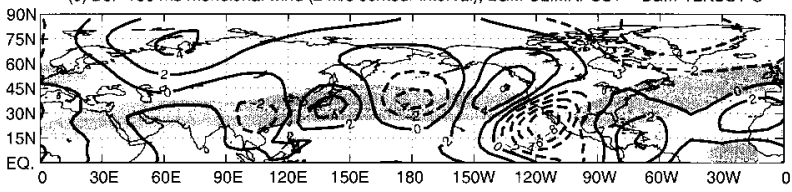

(d) DJF $150 \mathrm{mb}$ meridional wind (2 $\mathrm{m} / \mathrm{s}$ contour interval), LGM CLIMAPSST - LGM Y2KSST D

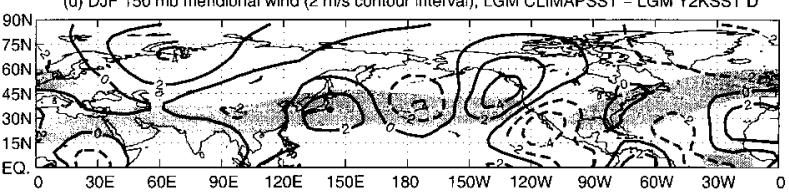

FIG. A9. Difference in DJF 150-mb meridional wind between CCM3 experiments LGM CLIMAPSST and these four experiments: (a) LGM Y2KSST A, (b) LGM Y2KSST B, (c) LGM Y2KSST C, and (d) LGM Y2KSST D. The contour interval for (a)-(d) is $2 \mathrm{~m}$ $\mathrm{s}^{-1}$ with dashed lines indicating negative contours. Regions where the DJF 150-mb zonal wind exceeds $30 \mathrm{~m} \mathrm{~s}^{-1}$ in experiment LGM CLIMAPSST are shaded to indicate the locations of the jets.

A9b). As a result, most wave energy is lost before it can reach the Atlantic jet, while more of the wave energy reaches the Atlantic jet and propagates around the globe to enhance the wave in the Pacific in Fig. A9b.

We also speculate that large topographical features inhibit the propagation of waves, at least in these experiments. This would explain the failure of waves to propagate from the subtropical cyclonic anomalies just west of the Himalaya in Figs. A3a and A4a, the lack of wave amplitude over the Laurentide ice sheet, and the decrease in wave amplitude seen as waves pass over the Fennoscandian ice sheet in Figs. A3b-d and A4b. The wave trains that propagate across Eurasia in Figs. $\mathrm{A} 4 \mathrm{c}$ and $\mathrm{A} 4 \mathrm{~d}$ appear to maintain their amplitude because they pass south of the Fennoscandian ice sheet.

While we have not proven that our explanations for the midlatitude circulation anomalies due to the CLIMAP tropical SSTs are correct, the mechanisms described above provide a plausible explanation for the modeled circulation changes. These results indicate that tropical convection can affect subtropical circulation by interacting with transients to produce cyclonic (anticyclonic) anomalies poleward of regions of decreased (increased) convection, and by changing upper-level zonal winds to affect the ability of Rossby waves to propagate equatorward south of the jet exit regions. These subtropical circulation anomalies in turn excite midlatitude wave trains which appear to be enhanced (a) DJF $150 \mathrm{mb}$ meridional wind (2 $\mathrm{m} / \mathrm{s}$ contour interval), LGM Y2KSST BCD - LGM Y2KSST ABCD
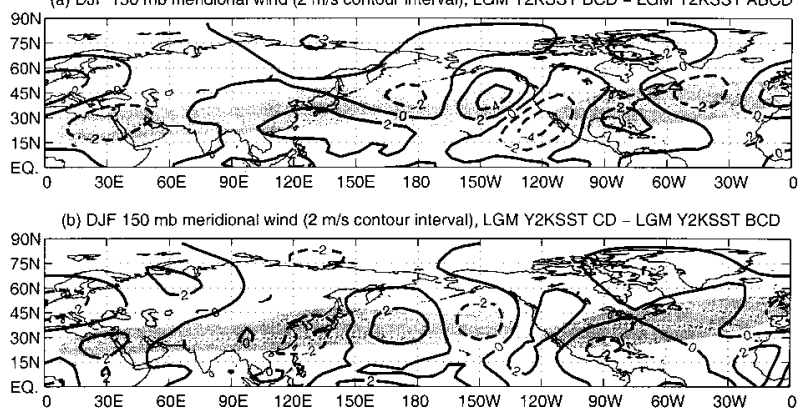

(c) DJF 150 mb meridional wind (2 $\mathrm{m} / \mathrm{s}$ contour interval), LGM YQKSST AB - LGM Y2KSST ABC

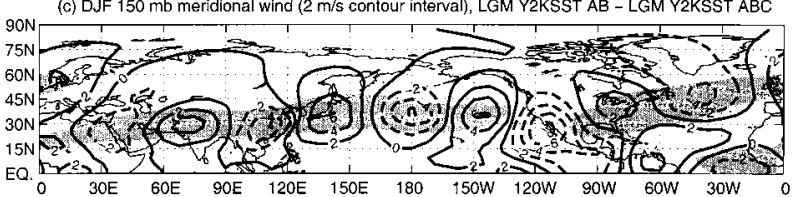

(d) DJF $150 \mathrm{mb}$ meridional wind (2 m/s contour interval), LGM Y2KSST ABC - LGM Y2KSST ABCD

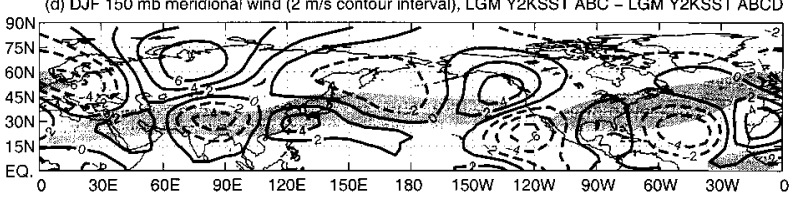

FIG. A10. Difference in DJF 150-mb meridional wind between these four pairs of CCM3 experiments: (a) LGM Y2KSST BCD LGM Y2KSST ABCD, (b) LGM Y2KSST CD - LGM Y2KSST BCD, (c) LGM Y2KSST AB - LGM Y2KSST ABC, and (d) LGM Y2KSST ABC - LGM Y2KSST ABCD. The contour interval for (a)-(d) is $2 \mathrm{~m} \mathrm{~s}^{-1}$ with dashed lines indicating negative contours. Regions where the DJF 150-mb wind exceeds $30 \mathrm{~m} \mathrm{~s}^{-1}$ in the first of the two experiments differenced in each are shaded to indicate the locations of the jets.

by transients in the jet exit regions, guided by the subtropical jets, and damped by large topographical features. Of course, much more work is necessary to fully understand how tropical SST and convection anomalies affect circulation in the midlatitudes. We hope that the figures and discussion presented in this appendix inspire those who are better equipped to think about this problem to perform further studies on the mechanisms described here.

\section{REFERENCES}

Ambrizzi, T., and B. J. Hoskins, 1997: Stationary Rossby-wave propagation in a baroclinic atmosphere. Quart. J. Roy. Meteor. Soc., 123, 919-928.

Bigg, G. R., M. R. Wadley, D. P. Stevens, and J. A. Johnson, 1998: Simulations of two last glacial maximum ocean states. Paleoceanography, 13, 340-351.

Broccoli, A. J., 2000: Tropical cooling at the last glacial maximum: An atmosphere-mixed layer ocean model simulation. J. Climate, 13, 951-976.

_ , and S. Manabe, 1987: The influence of continental ice, atmospheric $\mathrm{CO}_{2}$, and land albedo on the climate of the last glacial maximum. Climate Dyn., 1, 87-99.

Bush, A. B. G., and S. G. H. Philander, 1998: The role of oceanatmosphere interactions in tropical cooling during the last glacial maximum. Science, 279, 1341-1344.

CLIMAP Project Members, 1981: Seasonal Reconstruction of the 
Earth's Surface at the Last Glacial Maximum. Map and Chart Series, Vol. 36, Geological Society of America, 18 pp.

Curry, W. B., and D. W. Oppo, 1997: Synchronous, high-frequency oscillations in tropical sea surface temperatures and North Atlantic Deep Water production during the last glacial cycle. $\mathrm{Pa}$ leoceanography, 12, 1-14.

Dong, B., and P. J. Valdes, 1998: Simulations of the last glacial maximum climates using a general circulation model: Prescribed versus computed sea surface temperatures. Climate Dyn., 14, 571-591.

Garreaud, R. D., and D. S. Battisti, 1999: Interannual (ENSO) and interdecadal (ENSO-like) variability in the Southern Hemisphere tropospheric circulation. J. Climate, 12, 2113-2123.

Guilderson, T. P., R. G. Fairbanks, and J. L. Rubenstone, 1994: Tropical temperature variations since 20000 years ago: Modulating interhemispheric climate change. Science, 263, 663-665.

Hall, N. M. J., P. J. Valdes, and B. Dong, 1996: The maintenance of the last great ice sheets: A UGAMP GCM study. J. Climate, 9, $1004-1019$.

Held, I. M., S. W. Lyons, and S. Nigam, 1989: Transients and the extratropical response to El Niño. J. Atmos. Sci., 46, 163-174.

Hostetler, S. W., and A. C. Mix, 1999: Reassessment of ice-age cooling of the tropical ocean and atmosphere. Nature, 399, 673-676.

Hurrell, J. W., J. J. Hack, B. A. Boville, D. L. Williamson, and J. T. Kiehl, 1998: The dynamical simulation of the NCAR Community Climate Model Version 3 (CCM3). J. Climate, 11, 1207-1236.

Huybrechts, P., and S. T'siobbel, 1995: Thermomechanical modelling of Northern Hemisphere ice sheets with a two-level mass balance parameterization. Ann. Glaciol., 21, 111-116.

Joussaume, S., 1993: Paleoclimatic tracers: An investigation using an atmospheric general circulation model under ice age conditions. Part 1: Desert dust. J. Geophys. Res., 98, 2767-2805.

Kiehl, J. T., J. J. Hack, G. B. Bonan, B. A. Boville, B. P. Brieglieb, D. L. Williamson, and P. J. Rasch, 1996: Description of the NCAR Community Climate Model (CCM3). NCAR Tech. Note NCAR/TN420 + STR, 152 pp. [Available from NCAR, Boulder, CO 80307.]

Levitus, S., 1982: Climatological Atlas of the World Ocean. NOAA Professional Paper 13, 173 pp. and 17 microfiche.

Mix, A. C., A. E. Morey, N. G. Pisias, and S. W. Hostetler, 1999: Foraminiferal faunal estimates of paleotemperature: Circumventing the no-analog problem yields cool ice age tropics. $\mathrm{Pa}$ leoceanography, 14, 350-359.
Peltier, W. R., 1994: Ice age paleotopography. Science, 273, 195201.

Rind, D., 1987: Components of the ice age circulation. J. Geophys. Res., 92, 4241-4281.

— maximum and CLIMAP sea-surface temperature estimates: Are they consistent? Quat. Res., 24, 1-22.

Roe, G. H., 1999: Wobbly winds in an ice age: The mutual interaction between the great continental ice sheets and atmospheric stationary waves. Ph.D. thesis, Massachusetts Institute of Technology, $236 \mathrm{pp}$. [Available from Massachusetts Institute of Technology, 77 Massachusetts Ave., Cambridge, MA 02139-4307.]

Ropelewski, C. F., and M. S. Halpert, 1996: Quantifying Southern Oscillation-precipitation relationships. J. Climate, 9, 10431059.

Simmons, A. J., J. M. Wallace, and G. W. Branstator, 1983: Barotropic wave propagation and instability, and atmospheric teleconnection patterns. J. Atmos. Sci., 40, 1363-1392.

Stute, M., M. Forster, H. Frischkorn, A. Serejo, J. F. Clark, P. Schlosser, W. S. Broecker, and G. Bonani, 1995: Cooling of tropical Brazil $\left(5^{\circ} \mathrm{C}\right)$ during the last glacial maximum. Science, 269, 379383.

Tarasov, L., and W. R. Peltier, 1997: Terminating the $100 \mathrm{kyr}$ ice age cycle. J. Geophys. Res., 102, 21 665-21 693.

Thompson, L. G., E. Mosley-Thompson, M. E. Davis, P.-N. Lin, K. A. Henderson, J. Cole-Dai, J. F. Bolzan, and K.-B. Liu, 1995: Late glacial stage and Holocene tropical ice core records from Huascaran, Peru. Science, 269, 46-50.

Trenberth, K. E., G. W. Branstator, D. Karoly, A. Kumar, N.-C. Lau, and C. Ropelewski, 1998: Progress during TOGA in understanding and modeling global teleconnections associated with tropical sea surface temperatures. J. Geophys. Res., 103, 14 291-14 324.

Weaver, A. J., M. Eby, A. F. Fanning, and E. C. Wiebe, 1998: Simulated influence of carbon dioxide, orbital forcing and ice sheets on the climate of the Last Glacial Maximum. Nature, 394, 847 853

Webb, R. S., D. H. Rind, S. J. Lehman, R. J. Healy, and D. Sigman, 1997: Influence of ocean heat transport on the climate of the Last Glacial Maximum. Nature, 385, 695-699.

Webster, P. J., and J. R. Holton, 1982: Cross-equatorial response to middle-latitude forcing in a zonally varying basic state. J. Atmos. Sci., 39, 722-733.

Zhang, Y., J. M. Wallace, and D. S. Battisti, 1997: ENSO-like interdecadal variability: 1900-93. J. Climate, 10, 1004-1020. 